\title{
A descriptive and comparative neurocranium morphology of Anguilliformes fishes in Taiwan waters
}

\author{
MARITES RAMOS-CASTRO ${ }^{1}$, KAR-HOE LOH ${ }^{2} \&$ HONG-MING CHEN ${ }^{1,3^{*}}$ \\ ${ }^{\prime}$ Department of Aquaculture, College of Life Sciences, National Taiwan Ocean University, Keelung, 20224, Taiwan \\ =" maritescastro22@yahoo.com; @ https://orcid.org/0000-0002-4265-3865 \\ ${ }^{2}$ Institute of Ocean and Earth Sciences, Universiti Malaya, Kuala Lumpur 50603, Malaysia \\ "khloh@um.edu.my; 이ttps://orcid.org/0000-0001-8406-6485 \\ ${ }^{3}$ Center of Excellence for the Oceans, National Taiwan Ocean University, Keelung, 20224, Taiwan \\ "Corresponding author. "hmchen@mail.ntou.edu.tw; @ https://orcid.org/0000-0002-3921-2022
}

\begin{abstract}
Taiwan is one of the richest in the world in terms of eel fauna. In this study, we examined the osteological and morphological characteristics of eels under order Anguilliformes. Furthermore, we focused on the neurocranium of total of 30 Anguilliformes fishes under family Congridae (10), Muraenesocidae (1), Muraenidae (7), Nemichthyidae (1), Nettastomatidae (2), Ophichthidae (5), Synaphobranchidae (4), which are caught in Taiwanese waters. This paper shows the results of a comparative study on osteological characters of the neurocranium including the ratio of seven length characters using its NCL (neurocranium length), NCW (neurocranium width), OBL (orbit length), MFW (maximum frontal width), NCDB (neurocranium depth at basisphenoid), PEVW (premaxilla-ethmovomer width) and mPOBL (mid pre-orbital length), and 20 morphological diagnostic characters for 30 eel species. Results shows that species under family Nemichthyidae and Nettastomatidae have the highest values on the ratio of NCL/MFW, NCL/NCDB, and NCW/mPOBD. In morphological characters, it shows that species of the same family mostly share similar formation of the PEV plate and frontal structure. The usage of the length measurements and morphological diagnostic characters of neurocranium allowed for a more in depth understanding of how similar or different these eels can be. The neurocranial description and morphological characters may prove valuable for identification purposes and might be necessary tool for further studies on the status of order Anguilliformes.
\end{abstract}

Key words: Anguilliformes, eel, osteology, neurocranium, morphology

\section{Introduction}

Anguilliform fishes are generally elongated, which can reach $4 \mathrm{~m}(13 \mathrm{ft})$ in total length in the slender giant moray (McCosker,1998). They usually inhabit marine, brackish, and freshwater. Adults range in weight from $30 \mathrm{~g}$ to over $25 \mathrm{~kg}$, they possess no pelvic fins, and many species also lack pectoral fins. Scales usually absent or, if present, cycloid and embedded, (Froese \& Pauly, 2020). The Taiwan ichthyofauna, particularly the eel fauna (orders Anguilliformes and Saccopharyngiformes), is large and diverse (Ho et al., 2018). According to the latest annotated checklist of the eels of Taiwan, it is composed of 14 families and 232 species, and many additional species were reserved for further study. Several studies in classification and identification of eels were based on morphology and/or morphometric (Nelson, 1966; Böhlke, 1982; Robins, 1989), and genetic evidence (Vasconcelos, 2009; Tawa et al., 2012), which sometimes result in disagreement of DNA analysis and morphological comparisons in terms of phylogenetic relationships within the order (Wang et al., 2003).

Furthermore, there are studies focusing on functional morphology and discovered some interesting specializations, such as head-first burrowing in the Moringuidae (De Schepper et al., 2005, 2007), a unique system of prey transport using highly specialized pharyngeal jaws in the Muraenidae (Mehta \& Wainwright, 2007), and the description of the most basal, extant clade (genus Protanguilla) and its morphology, strengthening comparisons of derived morphologies across Anguilliformes (Johnson et al., 2012). In family Muraenidae, there are dietary studies 
that described and classified species mainly based on their cranial morphology, oral jaws, and dentition (Mehta, 2009), as well as described neurocranium morphology to differentiate the two subfamilies of Uropterygiinae and Muraeninae (Ramos-Castro et al., 2020), whereas other studies used otoliths in the morphological classification of families under order Anguilliformes (Chulin \& Chen, 2013).

Osteology is the study of the skeletal structure of fish which helps in understanding the variation of bone forms among different species. It is regarded as the most reliable tool for taxonomists and is used in tracing out the interrelationship between and within the group. This helps in understanding the important taxonomic characters for identification, classification, and comparison at the species, generic, family, or at the higher level (Gosline, 1967; Rosenblatt, 1967; Robins \& Robins, 1971; James, 1985; Böhlke et al., 1989).

During the past few years, few techniques have been widely applied to evolutionary studies, taxonomic examination and biogeographic analyses of eels (Ege, 1939; Watanabe et al., 2004, 2009; Arai et al., 2015). However, the application of osteological and morphological characteristics on eels was limited in exploration most likely due to the loss or fusion of many of their bones (Asano, 1962; Hulet, 1978; Böhlke et al., 1989). Therefore, this study focused on anguilliform fishes found in the waters of Taiwan specifically 30 species that belong to the families Congridae, Muraenesocidae, Muraenidae, Nemichthyidae, Nettastomatidae, Ophichthidae, and Synaphobranchidae.

Generally, the aim of this study was to list Anguilliformes fishes from Taiwan waters and to describe the neurocranium of species from seven families compressively based on the osteological attributes. This helps in understanding the important characters for identification and classification of fish at the family level. It is also hoped that this study could increase the knowledge on the osteology of the anguillid eels in general, as well as pave the way for future works concerning the comparative, anatomy, morphology, paleontology, and particularly the phylogeny of these Anguilliformes fishes.

\section{Materials and methods}

The specimens of moray eel were mainly caught by long-lines by the fishermen of Hualien and Taitung counties in eastern Taiwan, in 2000-2019. A total of 50 specimens, representing 30 individual species from seven families under order Anguilliformes, have been examined (Table 1). Specimens were individually photographed and their measurements were recorded following Böhlke et al. (1989). Total lengths were recorded to the nearest one-tenth of a centimeter $(0.1 \mathrm{~cm})$. Specimens were registered and assigned a catalog number to the collections of the Laboratory of Aquatic Ecology, Department of Aquaculture, National Taiwan Ocean University (TOU-AE). The head of each specimen was boiled for three to five minutes, depending on size. The skin and flesh were gently removed using tweezers. The remaining flesh attached to the bones was softened by soaking in $1 \% \mathrm{NaOH}$ solution for 20 to 30 minutes and was totally cleaned by brushing with a toothbrush. The eel skeletons were then air-dried for 24 hours.

The cranial and skeletal regions were compared according to Böhlke et al. (1989). The bony elements (Fig. 1) were also identified as basioccipital (BO) situated at the end of the occipital base; basisphenoid (BS), at the back of the orbital; ethmoid (E), median wall before the orbit and anterodorsal part of neurocranium; epiotic (EO), the upper element of pterotic; exoccipital (EX), the bone connected to the wing below pterotic; frontal $(\mathrm{F})$, the epidermal bones at the top of the skull above the eye, paired and separated by a ridge for some species; parasphenoid (PS), the median and elongated bone situated at the base of the neurocranium; parietal (PA), situated between the frontals and the upper occipital, often a pair; premaxillary-ethmovomer (PEV), premaxilla connecting to the ethmoid and vomer plate; prootic (PRO): site of the socket of hyomandibular attachment and situated lateroventrally under the sphenotic; pterotic (PT), the lower part of epiotic that expands laterally and protrudes posteriorly; pterosphenoid (PTS), bone connected to the base of the sphenotic; sphenotic (SP), small paired bone attached to the outer surface of the pterosphenoid; and supraoccipital (SO), the central bone on posterodorsal part of neurocranium.

Each neurocranium was photographed and measured to facilitate the comparison based on the length ratio and morphology. The measurements (Fig. 2) include neurocranium length (NCL), the distance between the anterior ethmoid and the distal end of the occipital; neurocranium width (NCW), the distance between the outer edges of the pterosphenoid on both posterior sides; orbit length (OBL), the maximum distance of the eye level; premaxillaryethmovomer width (PEVW), the maximum width from anteriormost part of premaxillary-ethmovomer; maximum frontal width (MFW), the maximum width from anterior wings of frontals; neurocranium depth at basisphenoid 
(NCDB), the greatest depth from top of frontals to the parasphenoid or the base of vomer at basisphenoid region; and mid pre-orbital depth (mPOBD), depth at the middle part of orbital region (Fig. 2). These measurements were done using digital calipers to the nearest $0.01 \mathrm{~mm}$.

To determine the length ratios and their relation in terms of sizes, the neurocranium length was used to divide by neurocranium width, orbit length, maximum frontal width, and neurocranium depth at basisphenoid; the neurocranium width was used to divide by premaxillary-ethmovomer width, mid pre-orbital depth, and maximum frontal width; the premaxillary-ethmovomer width was divided to mid pre-orbital depth; and orbit length was divided by premaxillary-ethmovomer width (Table 1). The neurocranium lengths and morphological characters were evaluated. The morphological terminologies on diagnosis follow Böhlke et al. (1989).

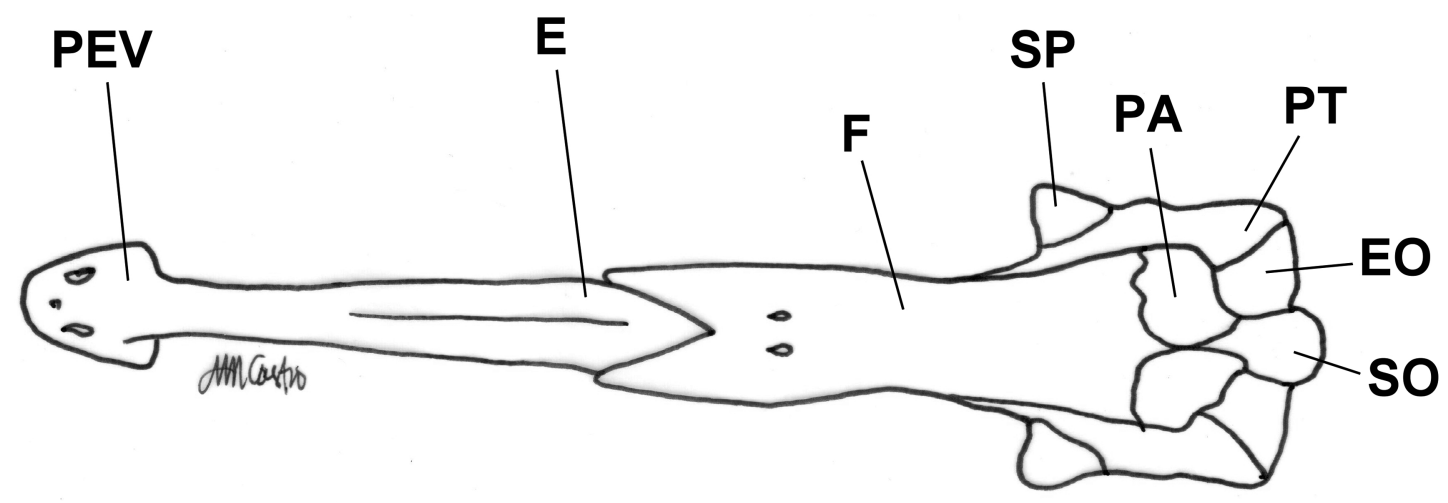

A

B

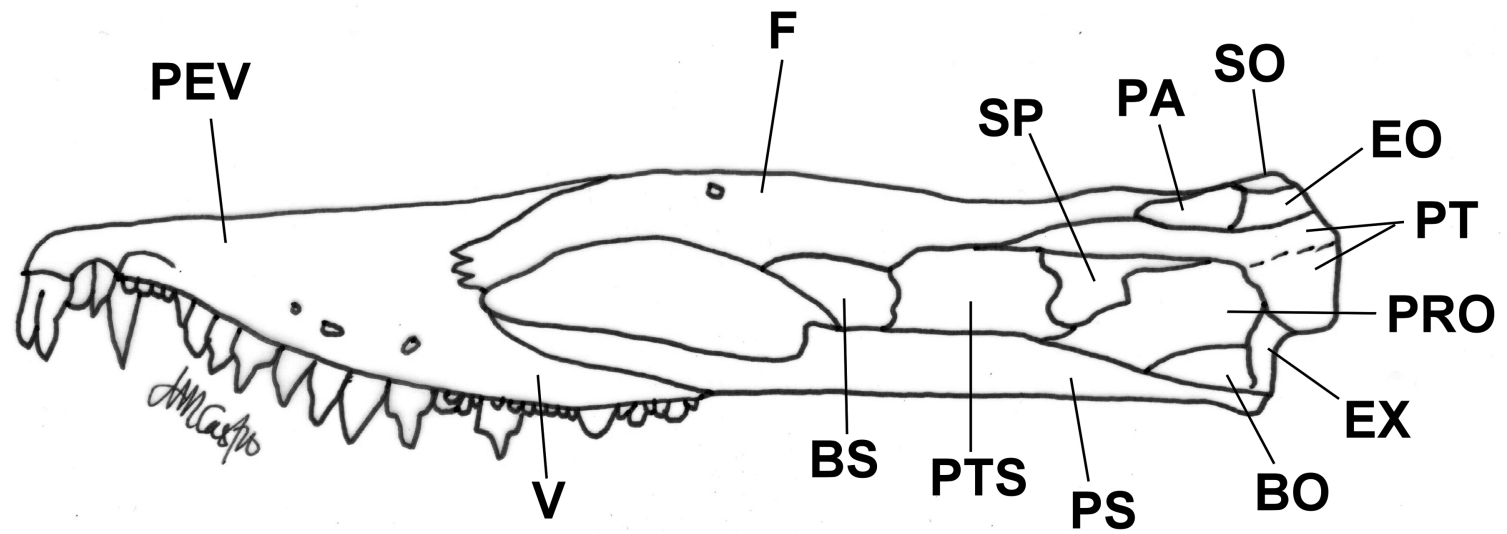

FIGURE 1. The name and abbreviation of the cranial skeletal elements. A. Dorsal view. B. Left lateral view. Abbreviations: BO: basioccipital; BS: basisphenoid; E: ethmoid; EX: exoccipital; EO: epiotic; F: frontal; PA: parietal; PS: parasphenoid; PEV: premaxillary-ethmovomer; PRO: prootic; PT: pterotic; PTS: pterosphenoid; SO: supraoccipital; SP: sphenotic.

\section{Results}

The neurocranium of each species is described here in detail, and further illustrated in both dorsal and lateral view (Figs. 3-18); some single bones are also illustrated with the characters used for the comparison each of the 30 Anguilliform fishes (Figs. 19-32). A detailed description of some bones, with variation noted, is given here. 


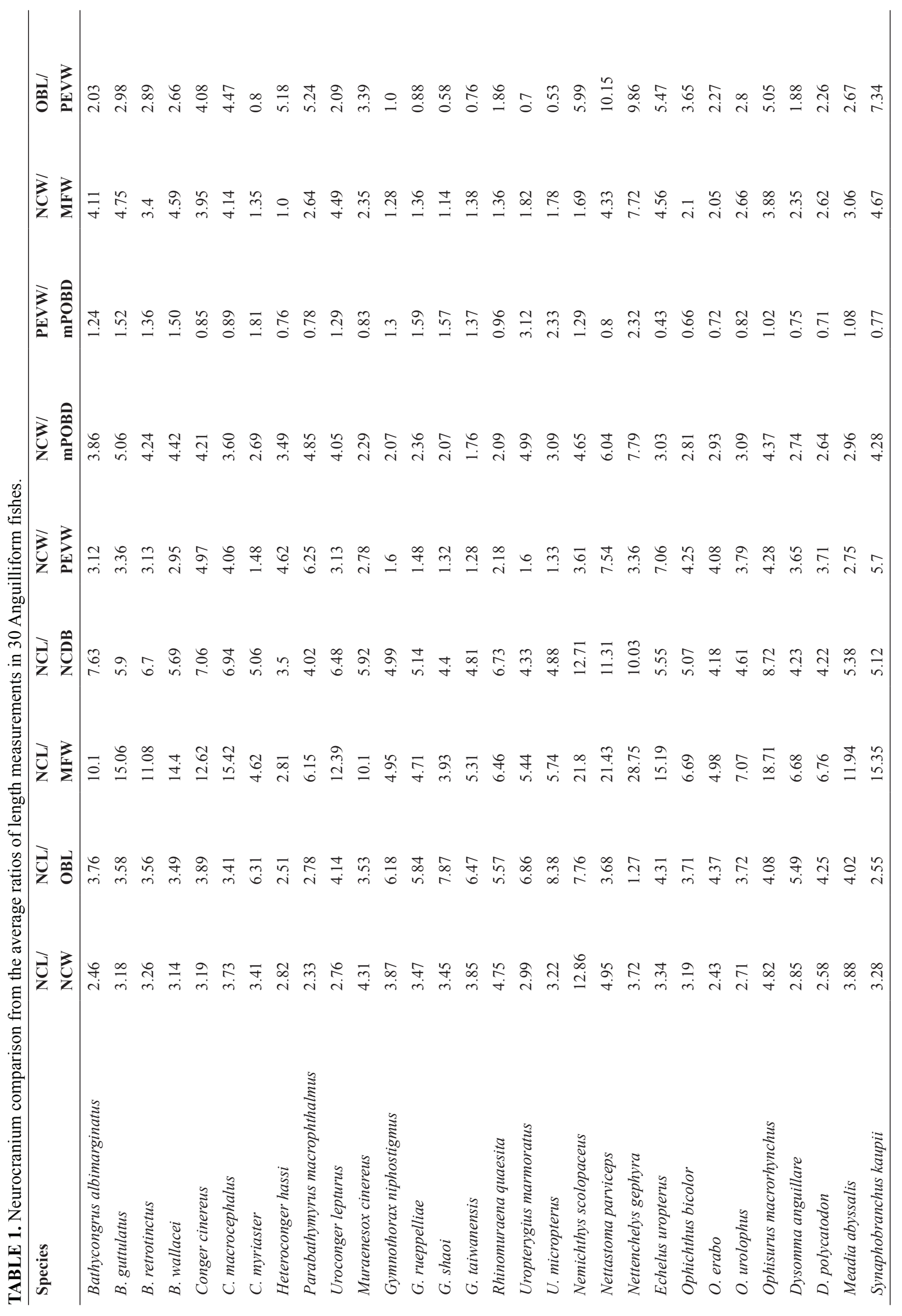



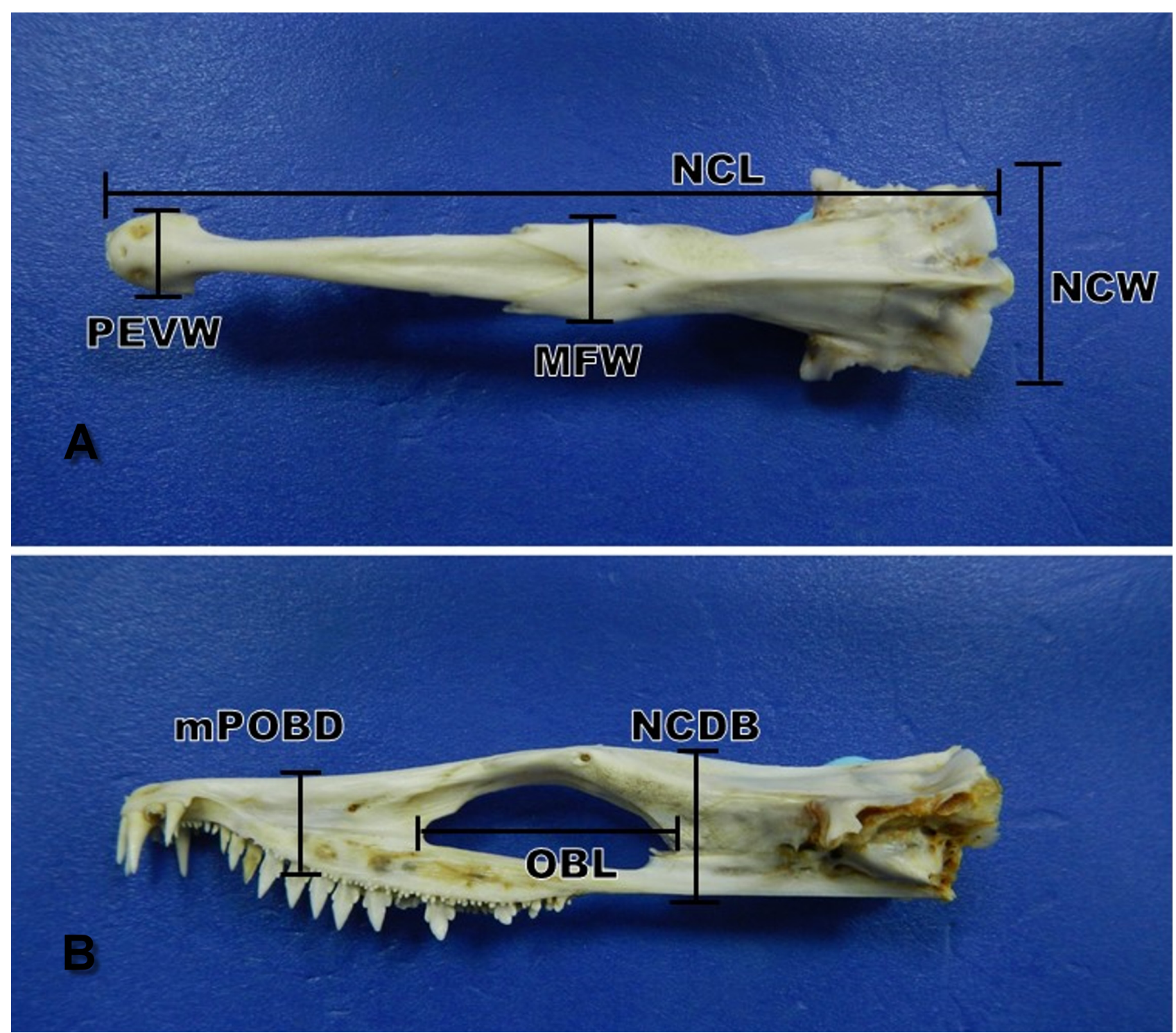

FIGURE 2. Location of the seven cranial measurements in Muraenesox cinereus, TOU-AE 7467, $89.3 \mathrm{~cm}$. TL. A. Dorsal and B. Left lateral view. Abbreviations: NCL, neurocranium length; NCW, neurocranium width; OBL, orbital length; PEVW, premaxillary-ethmovomer width; MFW, maximum frontal width; NCDB, neurocranium depth at basisphenoid; and mPOBD, mid pre-orbital depth.

\section{Family Congridae}

\subsection{Bathycongrus albimarginatus Huang, Ho, Chang, Smith \& Chen, 2018}

(Fig. 3 A-B)

Specimens examined and length measurements: One sample. TOU-AE 7374, $51.0 \mathrm{~cm}$ in TL. NCL: $42.5 \mathrm{~mm}$; NCW: $17.3 \mathrm{~mm}$; OBL: $11.29 \mathrm{~mm}$; PEVW: $5.55 \mathrm{~mm}$; MFW: $4.21 \mathrm{~mm}$; NCDB: $5.57 \mathrm{~mm}$; and mPOBD: 4.48 mm.

Diagnosis: The PEV plate is small and rectangular. The ethmoid is thin and long. The frontals are fused; the anterior end has a small lateral extension of paired cartilages, and develops a small notch at the sides. The orbit space is wide and triangular. The vomer has a sideways extension that is directed posteriorly. The sphenotics are long and narrow in the dorsal aspect and extend for most of the length of the parietals. In lateral view, the flange ascends anteriorly. A blunt end flange extends laterally from the anterior part of each sphenotic. The pterosphenoid has a sharp edge. The supraoccipital is reduced and ends in a small process. The posterior end of the epiotics and pterotics ascends outward. The basioccipital has a tumescent bulla. 


\subsection{Bathycongrus guttulatus (Günther, 1887)}

(Fig. 3 C-D)

Specimens examined and length measurements: Two samples. TOU-AE 7376, $38.5 \mathrm{~cm}$; TOU-AE 7377, $37.0 \mathrm{~cm}$, all in TL. NCL: $34.12-36.69 \mathrm{~mm}$; NCW: $10.47-11.86 \mathrm{~mm}$; OBL: 9.63-10.16 mm; PEVW: 3.29-3.36mm; MFW: 2.28-2.42 mm; NCDB: 5.95-6.04mm; and mPOBD: 2.03-2.39 mm.

Diagnosis: The PEV plate is small and square-shaped. The ethmoid is thin and long. The frontals are fused; the anterior end has a small lateral extension of paired cartilages. The orbit space is wide and triangular in shape. The vomer has a sideways extension that is directed posteriorly. The sphenotics are long and narrow in the dorsal aspect and extend for most of the length of the parietals. In lateral view, the flange is aligned and projects anteriorly. A tiny pointed triangular flange extends laterally from the anterior part of each sphenotic. The pterosphenoid has a sharp edge. The supraoccipital is reduced and ends in a small process. The posterior end of the epiotics and parietals ascends outward. The basioccipital has a tumescent bulla.
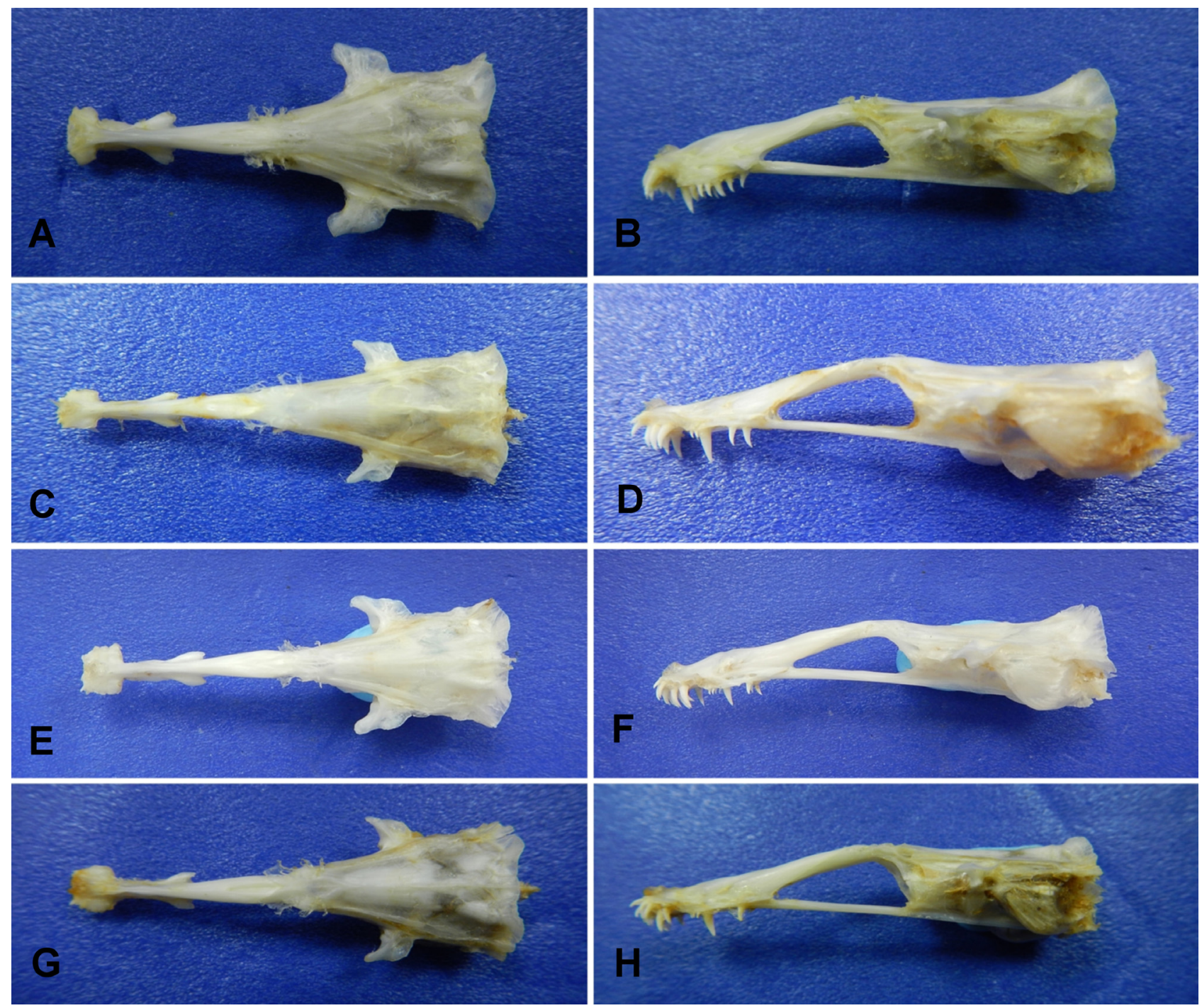

FIGURE 3. Dorsal and left lateral view of Bathycongrus albimarginatus, TOU-AE 7374, $51.0 \mathrm{~cm}$ TL (A, B); B. guttulatus, TOU-AE 7376, $38.5 \mathrm{~cm}$ TL (C, D); B. retrotinctus, TOU-AE 7618, $51.0 \mathrm{~cm}$ TL (E, F); and B. wallacei. TOU-AE 7327, 39.0 $\mathrm{cm}$ in $\mathrm{TL}(\mathrm{G}, \mathrm{H})$. 


\subsection{Bathycongrus retrotinctus (Jordan \& Snyder, 1901)}

(Fig. 3 E-F)

Specimens examined and length measurements: Two samples. TOU-AE 7618, $51.0 \mathrm{~cm}$; TOU-AE 7619, 29.0 cm, all in TL. NCL: 32.06-49.0 mm; NCW: 9.8-15.09 mm; OBL: 9.26-13.41 mm; PEVW: 2.72-5.66 mm; MFW: 3.63-3.7 mm; NCDB: 4.89-7.16 mm; and mPOBD: 2.04-4.11 mm.

Diagnosis: The PEV plate is small and square-shaped. The ethmoid is thin and long. The frontals are fused, the anterior end has a small lateral extension of paired cartilages. The orbit space is wide and triangular in shape. The vomer has a sideways extension that directed posteriorly. The sphenotics are long and narrow in the dorsal aspect and extend for most of the length of the parietals. In lateral view, the flange descends anteriorly. A tiny blunt flange extends laterally from the anterior part of each sphenotic. The pterosphenoid has a sharp edge. The supraoccipital is reduced and ends in a small process. The posterior end of the epiotics and pterotics ascends outward. The basioccipital has a tumescent bulla. Neurocranium has whitish coloration and thin structure.

\subsection{Bathycongrus wallacei (Castle, 1968)}

(Fig. $3 \mathrm{G}-\mathrm{H}$ )

Specimens examined and length measurements: One sample. TOU-AE 7327, $39.0 \mathrm{~cm}$ in TL. NCL: $39.31 \mathrm{~mm}$; NCW: $12.52 \mathrm{~mm}$; OBL: $11.27 \mathrm{~mm}$; PEVW: $4.24 \mathrm{~mm}$; MFW: $2.73 \mathrm{~mm}$; NCDB: $6.91 \mathrm{~mm}$; and mPOBD: $2.83 \mathrm{~mm}$.

Diagnosis: The PEV plate is a small square-shaped. Ethmoid is thin and long. Frontals are fused, the anterior end has a small lateral extension of paired cartilages. The orbit space is wide and triangular in shape. The vomer has a sideways extension that directed posteriorly. The sphenotics are long and narrow in the dorsal aspect and extend for most of the length of the parietals. In lateral view, the flange is aligned and projects anteriorly. A tiny and pointed end flange extends laterally from the anterior part of each sphenotic. Pterosphenoid is compact. The supraoccipital is reduced and ended in a small process. The posterior end of epiotics and pterotics ascends outward. The basioccipital has a tumescent bulla.

\subsection{Conger cinereus Rüppell in Klunzinger, 1871}

(Fig. 4 A-B)

Specimens examined and length measurements: Two samples. TOU-AE 7479, $83.8 \mathrm{~cm}$; TOU-AE 7671, $92.5 \mathrm{~cm}$; all in TL. NCL: 62.03-83.9 mm; NCW: 19.44-26.3 mm; OBL: 16.06-21.46 mm; PEVW: 3.67-5.66 mm; MFW: 4.01-8.59 mm; NCDB: 8.95-11.66 mm; and mPOBD: 4.73-6.1 mm.

Diagnosis: The PEV plate is elongated. The ethmoid is thin and long. The frontals are fused, the anterior end has paired pores, and a small lateral extension of paired cartilages. The orbit space is wide and triangular in shape. The vomer has a sideways extension that directed posteriorly. The sphenotics are long and narrow in the dorsal aspect and extend for most of the length of the parietals, and its anterior part forms a small shelf. In lateral view, the flange descends anteriorly. A tiny and pointed flange extends laterally from the anterior part of each sphenotic. The pterosphenoid is compact and has pores in the joint with the sphenotic. The supraoccipital is reduced but dorsally extends in a small process surpassing the proximal end of epiotics and pterotics. The basioccipital is broad but not swollen.

\subsection{Conger macrocephalus Kanazawa, 1958}

(Fig. 4 C-D)

Specimens examined and length measurements: Three samples. TOU-AE 7294, $59.6 \mathrm{~cm}$; TOU-AE 7310, 78.5 cm; TOU-AE 7328, $52.4 \mathrm{~cm}$; all in TL. NCL: 70.2-97.7 mm; NCW: 19.48-25.16 mm; OBL: 19.72-29.75 mm; PEVW: 4.95-6.34 mm; MFW: 4.03-6.2 mm; NCDB: 9.79-14.19 mm; and mPOBD: 5.29-7.1 mm.

Diagnosis: The PEV plate is small and oval-shaped. The ethmoid is thin, long, and has a shallow crease in the 
middle. The frontals are fused, the anterior end has paired pores, and a small lateral extension of paired cartilages. The orbit space is wide and triangular in shape. The vomer has a sideways extension that is directed posteriorly. The sphenotics are long and narrow in the dorsal aspect and extend for most of the length of the parietals, and the anterior part forms a small shelf. In lateral view, the flange descends anteriorly. A tiny and pointed end flange extends laterally from the anterior part of each sphenotic. The pterosphenoid is compact. The supraoccipital is reduced but dorsally extends in a small process surpassing the proximal end of epiotics and pterotics. The basioccipital is broad but not swollen.

\subsection{Conger myriaster (Brevoort, 1856)}

(Fig. 4 E-F)

Specimens examined and length measurements: One sample. TOU-AE 7241, $55.0 \mathrm{~cm}$ in TL. NCL: $49.37 \mathrm{~mm}$; NCW: $15.02 \mathrm{~mm}$; OBL: $11.30 \mathrm{~mm}$; PEVW: $4.03 \mathrm{~mm}$; MFW: $3.95 \mathrm{~mm}$; NCDB: $5.5 \mathrm{~mm}$; and mPOBD: $6.88 \mathrm{~mm}$.

Diagnosis: The PEV plate is small and oval-shaped. The ethmoid is thin, long, and has a shallow crease in the middle. The frontals are fused, the anterior end has paired pores and a small lateral extension of paired cartilages. The orbit space is wide and triangular in shape. The vomer has a sideways extension that is directed posteriorly. The sphenotics are long and narrow in the dorsal aspect and extend for most of the length of the parietals, and its anterior part forms a small shelf. In lateral view, it is slightly elevated and the flange descends anteriorly. A tiny and pointed end flange extends laterally from the anterior part of each sphenotic. Pterosphenoid is compact. The supraoccipital is reduced but dorsally extends in a small process surpassing the proximal end of the epiotics and pterotics. The basioccipital is broad but not swollen.

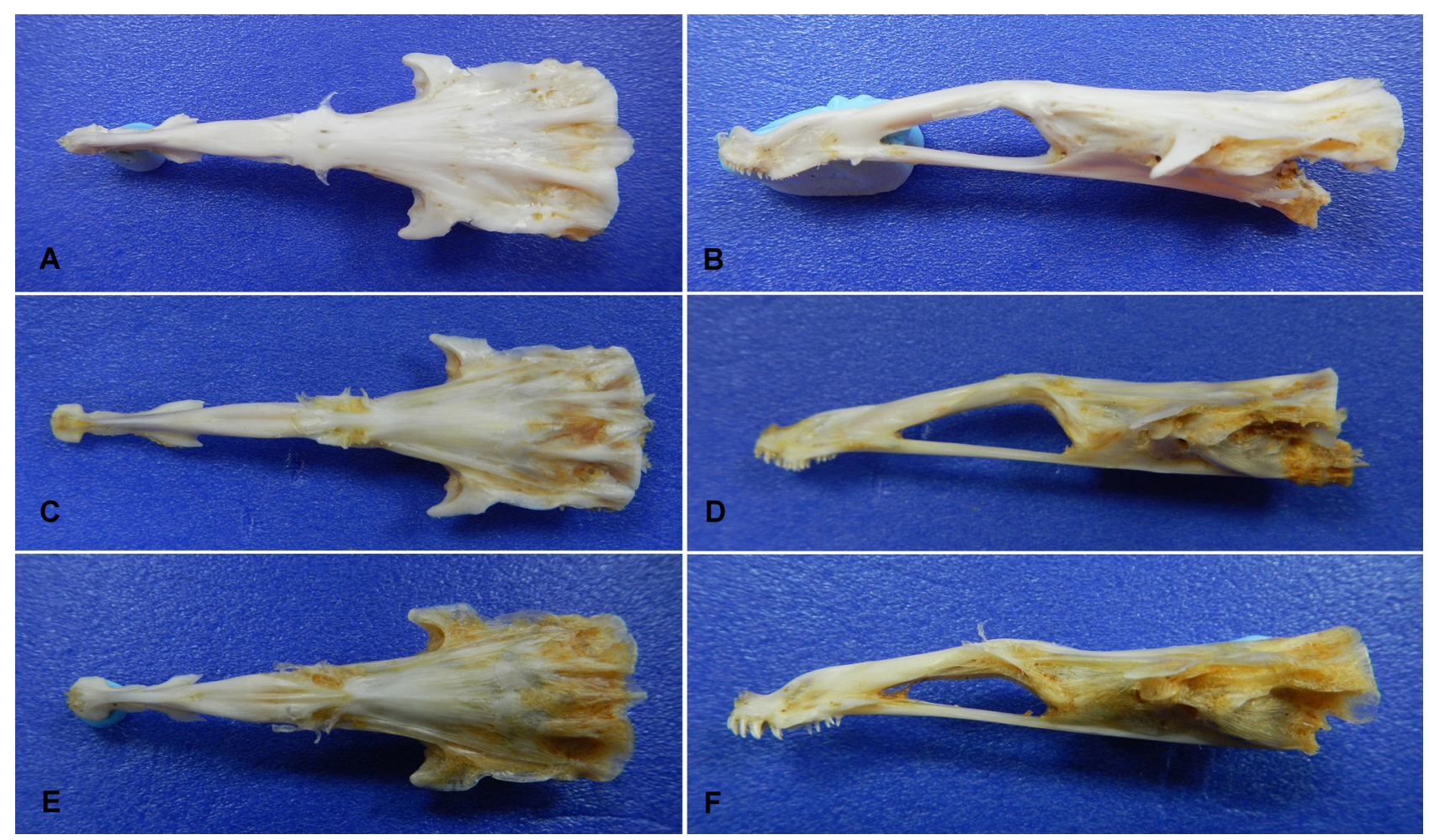

FIGURE 4. Dorsal and left lateral view of Conger cinereus, TOU-AE 7479, $83.8 \mathrm{~cm}$ TL (A, B); C. macrocephalus, TOU-AE 7294, $59.6 \mathrm{~cm}$ TL (C, D); and C. myriaster, TOU-AE 7241, $55.0 \mathrm{~cm}$ TL (E, F).

\subsection{Heteroconger hassi (Klausewitz \& Eibl-Eibesfeldt, 1959)}

(Fig. 5 A-B)

Specimens examined and length measurements: One sample. TOU-AE 7657, $23.8 \mathrm{~cm}$ in TL. NCL: $8.46 \mathrm{~mm}$; NCW: $3.0 \mathrm{~mm}$; OBL: $3.37 \mathrm{~mm}$; PEVW: $0.65 \mathrm{~mm}$; MFW: $3.01 \mathrm{~mm}$; NCDB: $2.42 \mathrm{~mm}$; and mPOBD: $0.86 \mathrm{~mm}$. 
Diagnosis: The PEV plate is small and elongated. The ethmoid is thin and short. The frontals are fused and have a smooth surface until the paired parietals. The orbit space is wide and oblong in shape. The parasphenoid has an elongated thin sideways extension that occupies the margin of the orbit. The sphenotics have a short flange and descend anteriorly. The pterosphenoid has a sharp edge. The supraoccipital and epiotics are reduced and end in front of the caudal border of the skull showing the exoccipitals from the ventrolateral part of the cranium. The pterotics enclose the lateral side. The basioccipital has a tumescent bulla.
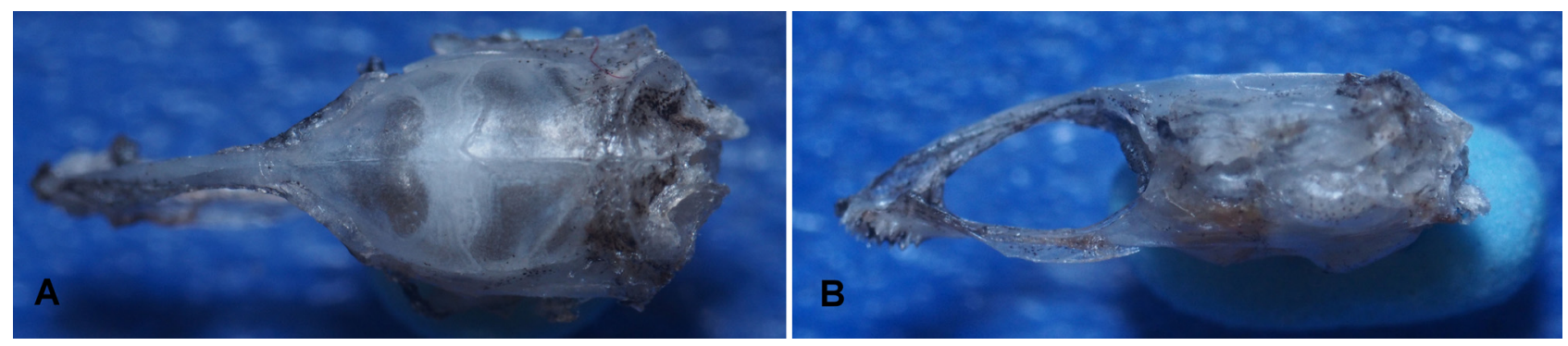

FIGURE 5. Dorsal and left lateral view of Heteroconger hassi, TOU-AE 7657, $23.8 \mathrm{~cm}$ TL (A, B).

\subsection{Parabathymyrus macrophthalmus Kamohara, 1938}

(Fig. $6 \mathrm{~A}-\mathrm{B})$

Specimens examined and length measurements: One sample. TOU-AE 7230, $33.0 \mathrm{~cm}$ in TL. NCL: $30.67 \mathrm{~mm}$; NCW: $13.18 \mathrm{~mm}$; OBL: $11.05 \mathrm{~mm}$; PEVW: $2.11 \mathrm{~mm}$; MFW: $4.99 \mathrm{~mm}$; NCDB: $7.63 \mathrm{~mm}$; and mPOBD: $2.72 \mathrm{~mm}$.

Diagnosis: The PEV plate is small and elongated. Ethmoid is laterally compressed, thin, and short and has a protruding process on the anterior end. The middle part of the ethmoid has paired sideways process that extends downward. Frontals are fused, displays ventral flange, and bears a small ridge that passes between parietals. The orbit space is wide and triangular in shape. The vomer has a sideways extension directed anteriorly. Parasphenoid is laterally compressed and thin. Basisphenoid has a small medial process directed towards the orbit. The sphenotics have an oblique rectangular-shaped flange and descend anteriorly. The pterosphenoid has a pointed edge. The supraoccipital spine is unobservable externally. The supraoccipital and epiotics ascend dorsally. The pterotics have a sharp edge that extends farther laterally. The basioccipital has a tumescent bulla.


FIGURE 6. Dorsal and left lateral view of Parabathymyrus macrophthalmus, TOU-AE 7230, $33.0 \mathrm{~cm}$ TL (A, B).

\subsection{Uroconger lepturus (Richardson, 1845)}

(Fig. 7 A-B)

Specimens examined and length measurements: Two samples. TOU-AE 7380, $34.0 \mathrm{~cm}$; TOU-AE 7410, $29.2 \mathrm{~cm}$; all in TL. NCL: $25.03 \mathrm{~mm}$; NCW: $9.07 \mathrm{~mm}$; OBL: $6.05 \mathrm{~mm}$; PEVW: $2.9 \mathrm{~mm}$; MFW: $2.02 \mathrm{~mm}$; NCDB: $3.86 \mathrm{~mm}$; and mPOBD: $2.24 \mathrm{~mm}$.

Diagnosis: The PEV plate is small but broad. Ethmoid is thin, long, and has a shallow crease in the middle. Frontals are fused, the anterior end has a small lateral extension of paired cartilages. The orbit space is wide, slightly compressed, and triangular in shape. The vomer has a sideways extension directed posteriorly. The sphenotics are long and narrow in the dorsal aspect and extend for most of the length of the parietals. In lateral view, the flange descends anteriorly. A tiny and blunt end flange extends laterally from the anterior part of each sphenotic. 
Pterosphenoid is compact. The supraoccipital is reduced and anterior than the proximal end of epiotics and pterotics. The basioccipital has a tumescent bulla.
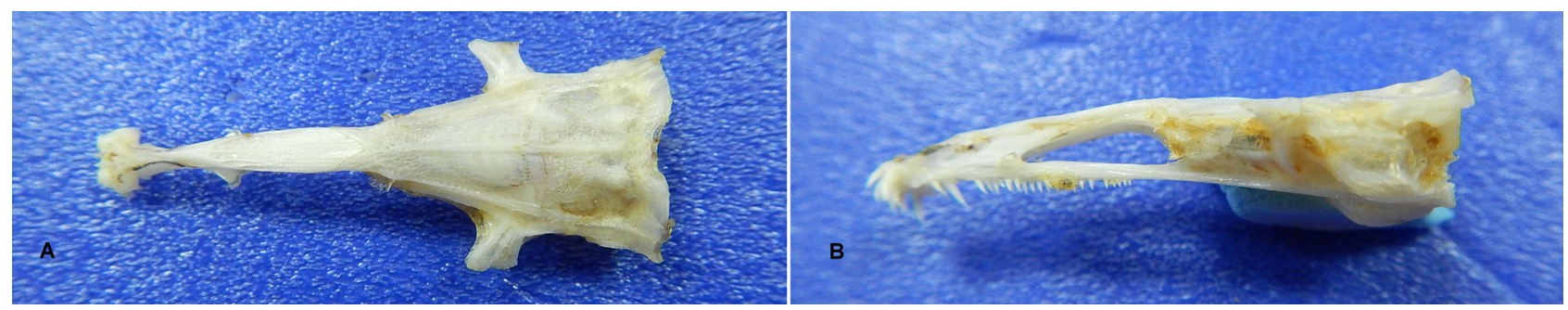

FIGURE 7. Dorsal and left lateral view of Uroconger lepturus, TOU-AE 7380, $34.0 \mathrm{~cm}$ TL (A, B).

\section{Family Muraenesocidae}

\subsection{Muraenesox cinereus (Forsskål, 1775)}

(Fig. 8 A-B)

Specimens examined and length measurements: Two samples. TOU-AE 7467, $89.3 \mathrm{~cm}$; TOU-AE 7469, $87.5 \mathrm{~cm}$; all in TL. NCL: 89.43-93.92 mm; NCW: 20.29-22.31 mm; OBL: 26.5-25.51 mm; PEVW: 7.64-7.71 mm; MFW: 8.74-9.46 mm; NCDB: $15.36-15.63 \mathrm{~mm}$; and mPOBD: 8.94-9.64mm.

Diagnosis: The PEV plate is small and oval in shape. Ethmoid is thin, long, and has a shallow crease in the middle. Frontals are fused and have a ridge in the midline, the anterior end has paired pores and a small lateral extension of paired cartilages directed anteriorly. The orbit space is wide and displays semi-oblong in shape. The posterodorsal margin of the vomer has a sideways extension. Basisphenoid has a small medial process directed towards the orbit. The sphenotics are long and narrow in the dorsal aspect and extend for most of the length of the parietals. In lateral view, the flange is slightly tilted and descends posteriorly. Pterosphenoid is compact and smooth. Supraoccipital extends dorsally and surpassing the proximal end of epiotics and pterotics. The basioccipital has a pointed base.
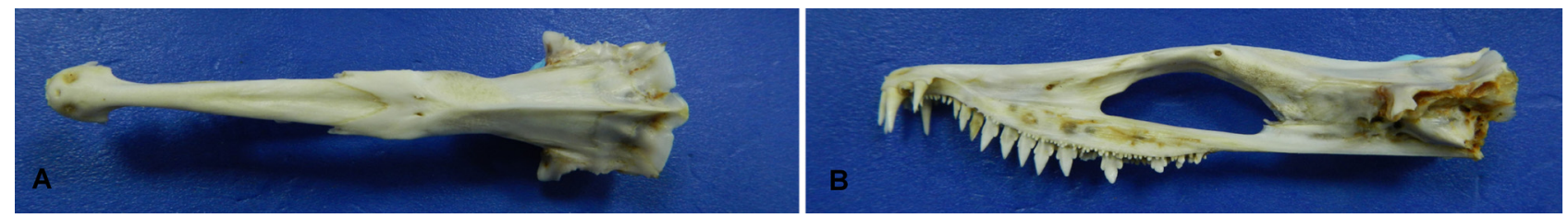

FIGURE 8. Dorsal and left lateral view of Muraenesox cinereus, TOU-AE 7467, $89.3 \mathrm{~cm}$ TL (A, B).

\section{Family Muraenidae}

\subsection{Gymnothorax niphostigmus Chen, Shao \& Chen, 1996}

(Fig. 9 A-B)

Specimens examined and length measurements: Two samples. TOU-AE 7633, $45.0 \mathrm{~cm}$; TOU-AE 7635, 36.5 cm; all in TL. NCL: 25.09-31.5 mm; NCW: 6.39-8.28 mm; OBL: 4.14-5.0 mm; PEVW: 3.95-5.22 mm; MFW: 5.02-6.42 mm; NCDB: 4.95-6.42mm; and mPOBD: 3.35-3.81 mm.

Diagnosis: The PEV plate is elongated. Ethmoid is thin and has a shallow groove at the posterior end. The paired frontals have visible suture at the joint. The anterior end has a blunt end lateral extension. The orbit space is moderately small and displays semi-oblong in shape. The posterodorsal margin of the PEV plate has a sideways extension that ascends dorsally. Basisphenoid has a small medial process directed towards the orbit. The sphenotics are short and directed downward. Pterosphenoid is compact and smooth. The paired parietals have pore in the joint. Supraoccipital ascends dorsally and surpassing the proximal end of epiotics. The basioccipital has a pointed base. 


\subsection{Gymnothorax rueppelliae (McClelland, 1844)}

(Fig. 9 C-D)

Specimens examined and length measurements: Three samples. TOU-AE 4342, $55.9 \mathrm{~cm}$; TOU-AE 4343, 62.6 $\mathrm{cm}$; TOU-AE 4344, 59.6 cm; all in TL. NCL: 36.89-42.07 mm; NCW: 10.09-12.2 mm; OBL: 6.19-7.33 mm; PEVW: 7.12-8.86 mm; MFW: 7.69-9.61 mm; NCDB: 7.02-8.77 mm; and mPOBD: 4.16-5.58 mm.

Diagnosis: The PEV plate is elongated. Ethmoid is thin and has a shallow groove at the posterior end. The paired frontals have visible suture at the joint. The orbit space is moderately small and displays quadrant in shape. The anterior end has paired pores and a small lateral paired extensions directed downwards. The posterodorsal margin of the PEV plate has a sideways extension that ascends dorsally. Basisphenoid has a small medial process directed towards the orbit. The sphenotics are short and directed downward. The pterosphenoid has a pointed edge. The paired parietals have pore in the joint. Supraoccipital ascends dorsally and surpassing the proximal end of epiotics. The basioccipital has a pointed base.

\subsection{Gymnothorax shaoi Chen \& Loh, 2007}

(Fig. 9 E-F)

Specimens examined and length measurements: Two samples. TOU-AE 4347, $66.9 \mathrm{~cm}$; TOU-AE 7637, 43.5 cm; all in TL. NCL: 29.81-44.37 mm; NCW: 8.2-13.55 mm; OBL: 3.83-5.57 mm; PEVW: 6.13-10.46 mm; MFW: 7.43-11.52 mm; NCDB: $6.75-10.12 \mathrm{~mm}$; and mPOBD: 3.87-4.76 mm.
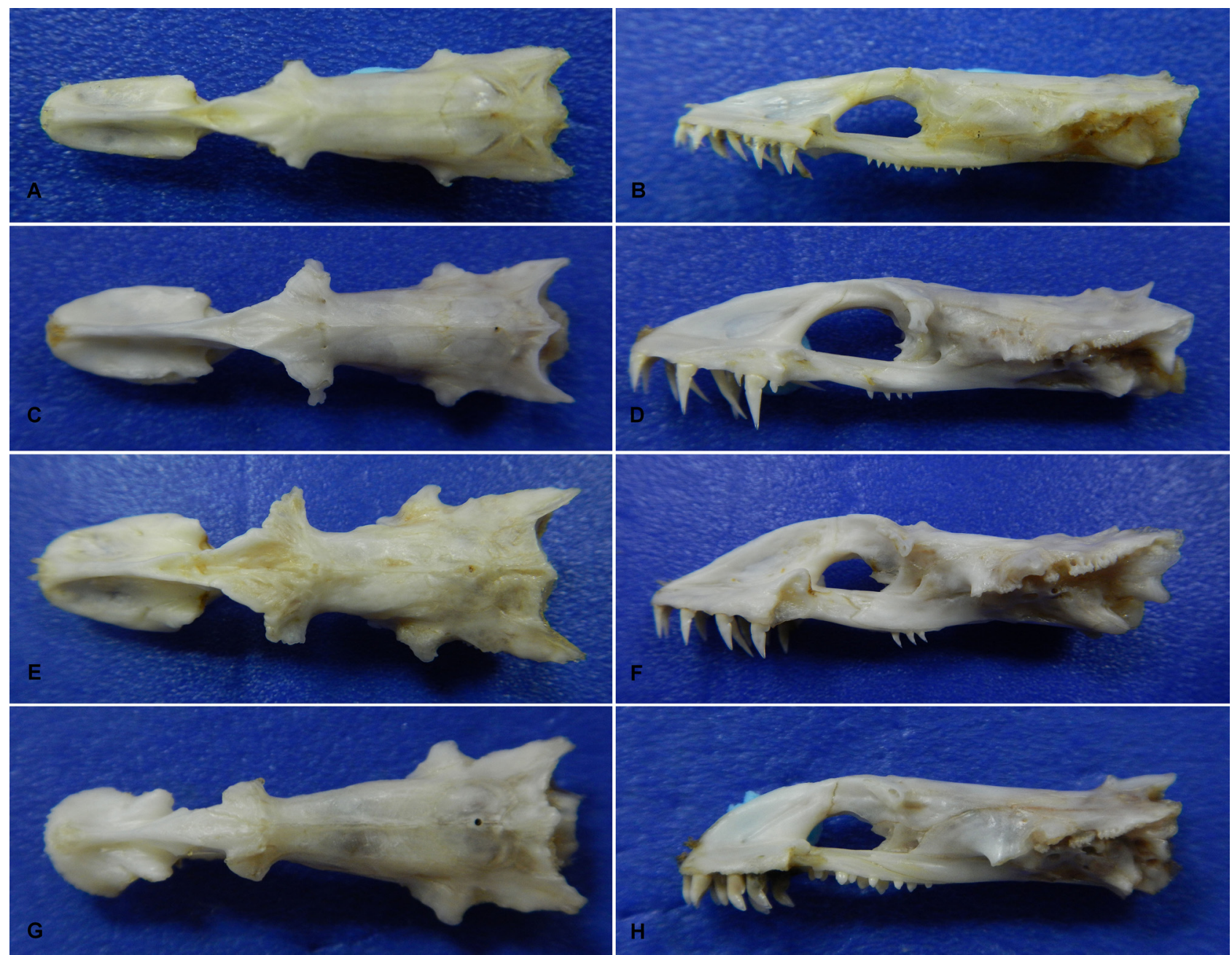

FIGURE 9. Dorsal and left lateral view of Gymnothorax niphostigmus, TOU-AE 7633, $45.0 \mathrm{~cm}$; TL (A, B); G. rueppelliae, TOU-AE 4342, $55.9 \mathrm{~cm}$ TL (C, D); G. shaoi, TOU-AE 4347, $66.9 \mathrm{~cm}$ TL (E, F); and G. taiwanensis. TOU-AE 7625, $53.3 \mathrm{~cm}$ $\mathrm{TL}(\mathrm{G}, \mathrm{H})$. 
Diagnosis: The PEV plate is elongated. Ethmoid is thin and has a shallow groove at the posterior end. The paired frontals have visible suture at the joint. The anterior end has a small lateral paired extension which ornamented over the exposed and elevated area of the dorsal part. The orbit space is small and displays triangular in shape. The posterodorsal margin of the PEV plate has a sideways extension that ascends dorsally. Basisphenoid has a small medial process directed towards the orbit. The sphenotics are short and directed posteriorly. The pterosphenoid is compact and smooth. The paired parietals have pore in the joint. Supraoccipital ascends dorsally and surpassing the proximal end of epiotics. The basioccipital has a pointed base.

\subsection{Gymnothorax taiwanensis Chen, Loh \& Shao, 2008}

(Fig. 9 G-H)

Specimens examined and length measurements: Two samples. TOU-AE 7625, $53.3 \mathrm{~cm}$; TOU-AE $7632,37.0 \mathrm{~cm}$; all in TL. NCL: 23.21-35.73 mm; NCW: 6.0-9.33 mm; OBL: 3.54-5.6 mm; PEVW: 4.54-7.5 mm; MFW: 4.61-6.4 mm; NCDB: $4.86-7.38 \mathrm{~mm}$; and mPOBD: $3.87-4.76 \mathrm{~mm}$.

Diagnosis: The PEV plate is elongated. Ethmoid is thin and has a shallow groove at the posterior end. The paired frontals have visible suture at the joint. The anterior end has paired pores and a small lateral paired extension. The orbit space is small and displays triangular in shape. The posterodorsal margin of the PEV plate has a sideways extension that ascends dorsally. Basisphenoid has a small medial process directed towards the orbit. The sphenotics are short and directed downwards. The pterosphenoid is compact but has a pointed edge. Supraoccipital ascends dorsally and surpassing the proximal end of epiotics and pterotics. The basioccipital has a pointed base.

\subsection{Rhinomuraena quaesita Garman, 1888}

(Fig. 10 A-B)

Specimens examined and length measurements: One sample. TOU-AE 7644, $81.5 \mathrm{~cm}$ in TL. NCL: $19.05 \mathrm{~mm}$; NCW: $4.01 \mathrm{~mm}$; OBL: $3.42 \mathrm{~mm}$; PEVW: $1.84 \mathrm{~mm}$; MFW: $2.95 \mathrm{~mm}$; NCDB: $2.83 \mathrm{~mm}$; and mPOBD: $1.92 \mathrm{~mm}$.

Diagnosis: The PEV plate is elongated. Ethmoid is thin. The paired frontals have visible suture at the joint. The anterior end has slightly excavated horizontally. The orbit space is moderately small and displays semi-oblong in shape. Basisphenoid has a small medial process directed towards the orbit. The sphenotics are short and directed downwards. The pterosphenoid is compact and smooth. Supraoccipital ascends dorsally and surpassing the proximal end of epiotics and pterotics. The basioccipital slightly reduced and tightly packed to the cranium.
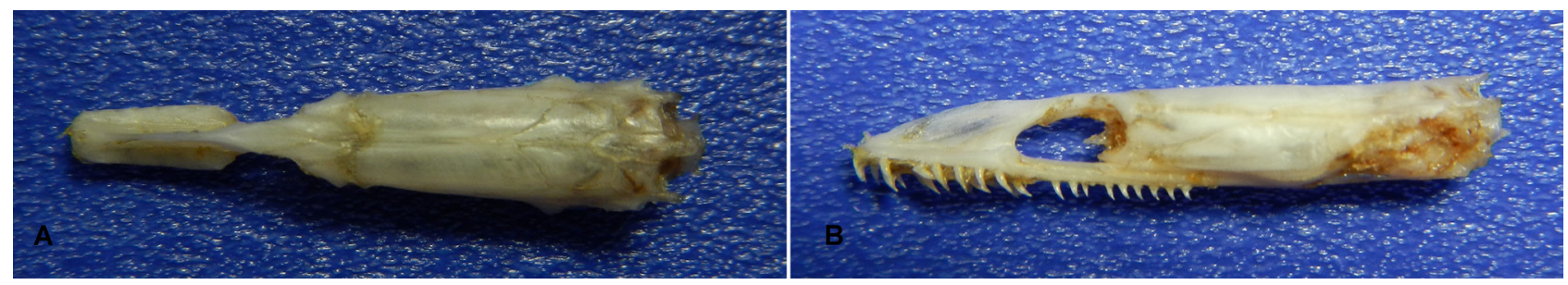

FIGURE 10. Dorsal and left lateral view of Rhinomuraena quaesita, TOU-AE 7644, $81.5 \mathrm{~cm}$ TL (A, B).

\subsection{Uropterygius marmoratus (Lacepède, 1803)}

(Fig. 11 A-B)

Specimens examined and length measurements: One sample. TOU-AE 7636, $63.0 \mathrm{~cm}$ in TL. NCL: $27.73 \mathrm{~mm}$; NCW: $9.28 \mathrm{~mm}$; OBL: $4.04 \mathrm{~mm}$; PEVW: $5.81 \mathrm{~mm}$; MFW: $5.1 \mathrm{~mm}$; NCDB: $6.41 \mathrm{~mm}$; and mPOBD: $1.86 \mathrm{~mm}$.

Diagnosis: The PEV plate is oval. Ethmoid is short and has a thin surface which discontinued toward the anterior part of PEV. The paired frontals have visible suture at the joint. The orbit space is moderately small; it displays semi-circle in shape due to an expanded process from the anterior wall of the orbit. The posterodorsal margin of the PEV plate has a sideways extension that ascends dorsally. Basisphenoid has a small medial process 
directed towards the orbit. The sphenotics are short and directed downwards. The pterosphenoid is compact and smooth. The paired parietals have pore in the joint. Supraoccipital ascends dorsally and surpassing the proximal end of epiotics. The basioccipital slightly reduced and tightly packed to the cranium.

\subsection{Uropterygius micropterus (Bleeker, 1852a)}

(Fig. 11 C-D)

Specimens examined and length measurements: Two samples. TOU-AE 7624, $28.4 \mathrm{~cm}$; TOU-AE 7640, 26.8 cm; all in TL. NCL: 12.90-14.59 mm; NCW: 3.95-4.63 mm; OBL: 1.46-1.92 mm; PEVW: 2.91-3.57 mm; MFW: 2.1-2.76 mm; NCDB: $2.7-2.95 \mathrm{~mm}$; and mPOBD: 1.26-1.52 mm.

Diagnosis: The PEV plate is oval. Ethmoid is short and has a thin surface which discontinued toward the anterior part of PEV. The paired frontals have visible suture at the joint. The orbit space is small and displays oblong. The posterodorsal margin of the PEV plate has a sideways extension that ascends dorsally. Basisphenoid has a small medial process directed towards the orbit. The sphenotics are short and directed downwards. The pterosphenoid is compact and smooth. Supraoccipital ascends dorsally and surpassing the proximal end of epiotics and pterotics. The basioccipital has no lump and tightly packed to the cranium.
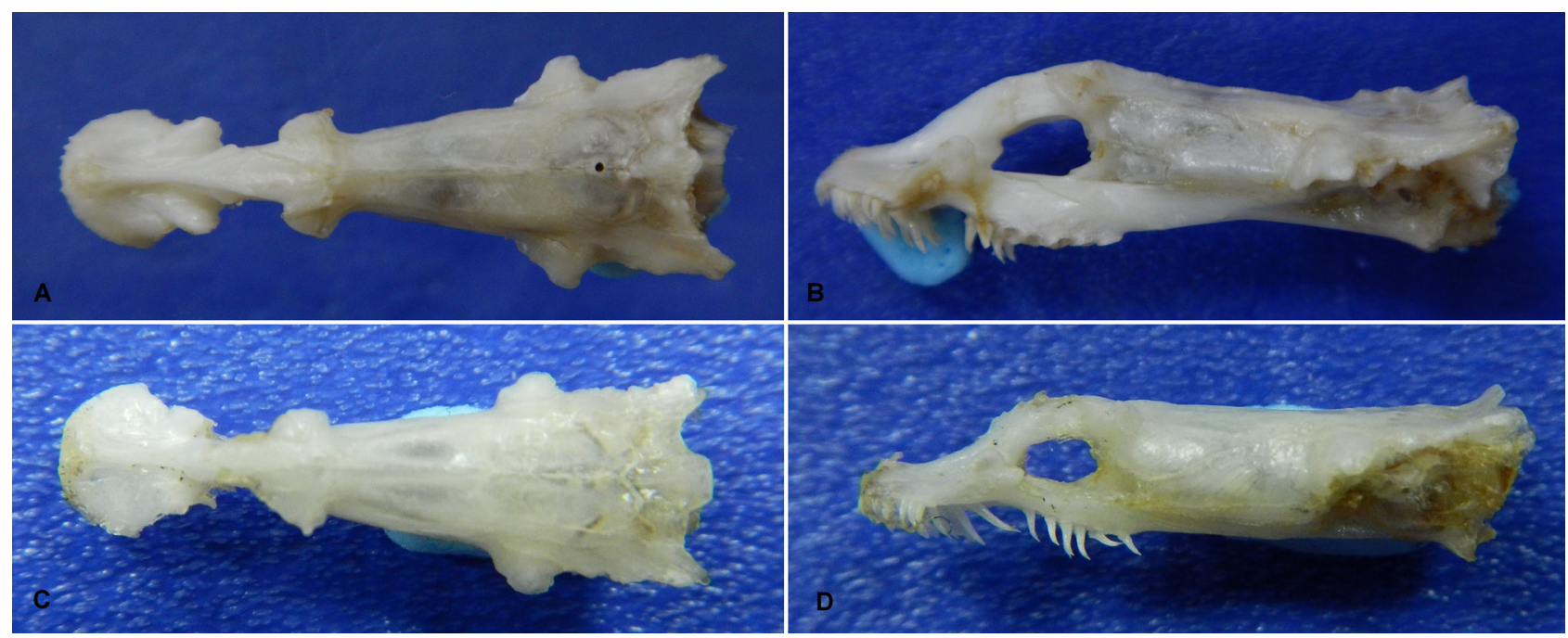

FIGURE 11. Dorsal and left lateral view of Uropterygius marmoratus, TOU-AE 7636, $63.0 \mathrm{~cm}$ in TL (A, B); and U. micropterus, TOU-AE 7624, $28.4 \mathrm{~cm}$ TL (C, D).

\section{Family Nemichthyidae}

\subsection{Nemichthys scolopaceus Richardson, 1848}

(Fig. 12 A-B)

Specimens examined and length measurements: One sample. TOU-AE 7678, $91.5 \mathrm{~cm}$ in TL. NCL: $77.17 \mathrm{~mm}$; NCW: $6.0 \mathrm{~mm}$; OBL: $9.95 \mathrm{~mm}$; PEVW: $1.66 \mathrm{~mm}$; MFW: $3.54 \mathrm{~mm}$; NCDB: $6.07 \mathrm{~mm}$; and mPOBD: $1.29 \mathrm{~mm}$.

Diagnosis: The premaxillae anterior end continues as an elongated cartilaginous plate. The PEV is thin, greatly elongated, and the tip is dorsally bent. The frontals are fused and bear a ridge at the posterior end until parietal (also fused). The orbit space is wide and displays semi-oblong in shape. The sphenotics are long, narrow, and pointed in the dorsal aspect and extend for most of the length of the parietals. In the lateral view, it is aligned and projects anteriorly. The pterosphenoid is compact. The supraoccipital is unobservable. The posterior end of epiotics and pterotics ascends outward. The basioccipital has no lump and tightly packed to the cranium. 

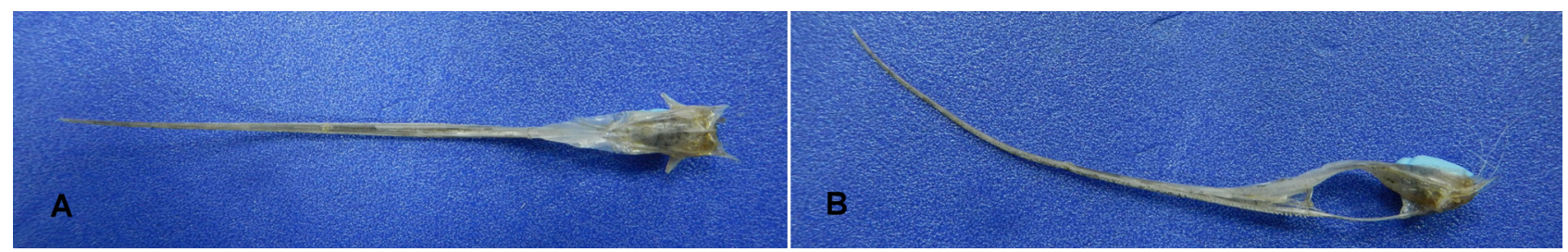

FIGURE 12. Dorsal and left lateral view of Nemichthys scolopaceus, TOU-AE 7678, $91.5 \mathrm{~cm}$ TL (A, B).

\section{Family Nettastomatidae}

\subsection{Nettastoma parviceps Günther, 1877}

(Fig. 13 A-B)

Specimens examined and length measurements: One sample. TOU-AE 7451, $52.5 \mathrm{~cm}$ in TL. NCL: $40.72 \mathrm{~mm}$; NCW: $8.22 \mathrm{~mm}$; OBL: $11.06 \mathrm{~mm}$; PEVW: $1.09 \mathrm{~mm}$; MFW: $1.9 \mathrm{~mm}$; NCDB: $3.6 \mathrm{~mm}$; and mPOBD: $1.36 \mathrm{~mm}$.

Diagnosis: The PEV plate is damage and unobservable. Ethmoid is thin and greatly elongated. Frontals are fused. The orbit space is long and compressed. The sphenotics are short and have a pointed edge that directed anteriorly. The pterosphenoid is highly intact to the cranium. The supraoccipital is unobservable. The epiotics and pterotics enclosed the posterior wall of the neurocranium whereas exoccipitals medially and the basioccipital ventrally. Neurocranium has yellowish coloration and very thin structure.
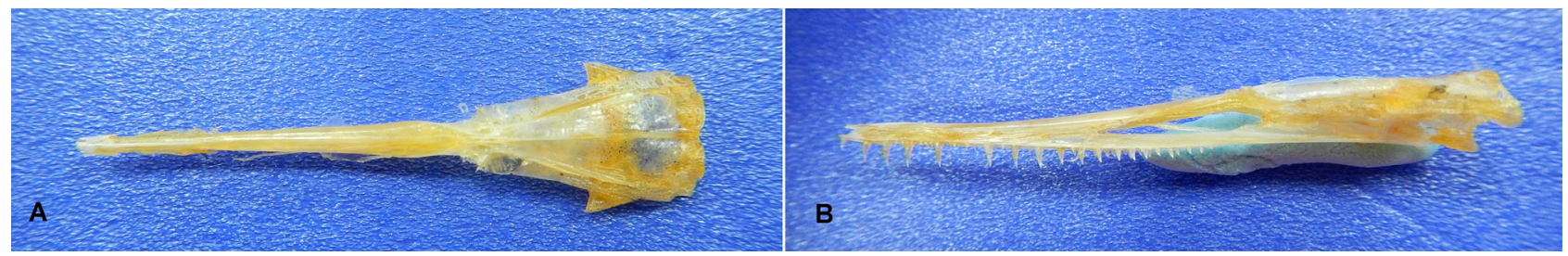

FIGURE 13. Dorsal and left lateral view of Nettastoma parviceps, TOU-AE 7451, $52.5 \mathrm{~cm}$ TL (A, B).

\subsection{Nettenchelys gephyra Castle \& Smith, 1981}

(Fig. 14 A-B)

Specimens examined and length measurements: One sample. TOU-AE 7452, $37.2 \mathrm{~cm}$ in TL. NCL: $31.91 \mathrm{~mm}$; NCW: $8.57 \mathrm{~mm}$; OBL: $25.15 \mathrm{~mm}$; PEVW: $2.55 \mathrm{~mm}$; MFW: $1.11 \mathrm{~mm}$; NCDB: $3.18 \mathrm{~mm}$; and mPOBD: $1.1 \mathrm{~mm}$.

Diagnosis: The PEV plate is small and oval. Ethmoid is thin and greatly elongated. Frontals are fused. The orbit space is long and compressed. The sphenotics are short and have a pointed edge that directed anteriorly. The pterosphenoid has a small extension process directed ventrally. The supraoccipital is unobservable. The epiotics and pterotics enclosed the posterior wall of the neurocranium whereas exoccipitals medially and the basioccipital ventrally.
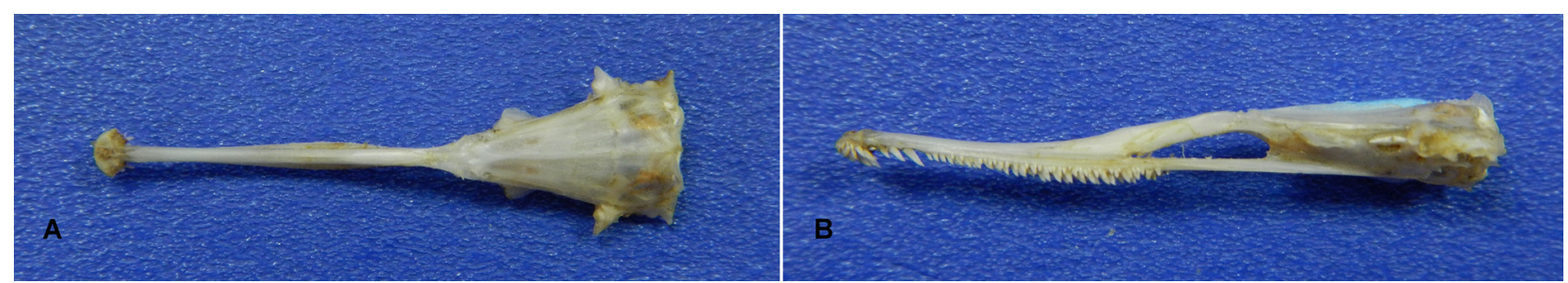

FIGURE 14. Dorsal and left lateral view of Nettenchelys gephyra, TOU-AE 7452, $37.2 \mathrm{~cm}$ TL (A, B). 


\section{Family Ophichthidae}

\subsection{Echelus uropterus (Temminck \& Schlegel, 1846)}

(Fig. 15 A-B)

Specimens examined and length measurements: Three samples. TOU-AE 7441, $36.2 \mathrm{~cm}$; TOU-AE 7442, 33.8 cm; TOU-AE 7443, $35.5 \mathrm{~cm}$; all in TL. NCL: 22.65-24.27 mm; NCW: 6.85-7.24 mm; OBL: 5.16-5.8 mm; PEVW: 0.97-1.05 mm; MFW: 1.2-2.84 mm; NCDB: 4.17-4.28 mm; and mPOBD: $2.13-2.7 \mathrm{~mm}$.

Diagnosis: The PEV plate is small and elongated. Ethmoid thin and long. The frontals are fused. The orbit space is wide and displays semi-oblong in shape. Basisphenoid has a small medial process directed towards the orbit. The sphenotics are short and directed downwards. The pterosphenoid is compact and smooth. The paired parietals and epiotics have angled lines visible from the inside of the cranium. The supraoccipital is short and ascends dorsally surpassing the proximal end of epiotics and pterotics. The basioccipital is tightly packed to the cranium.
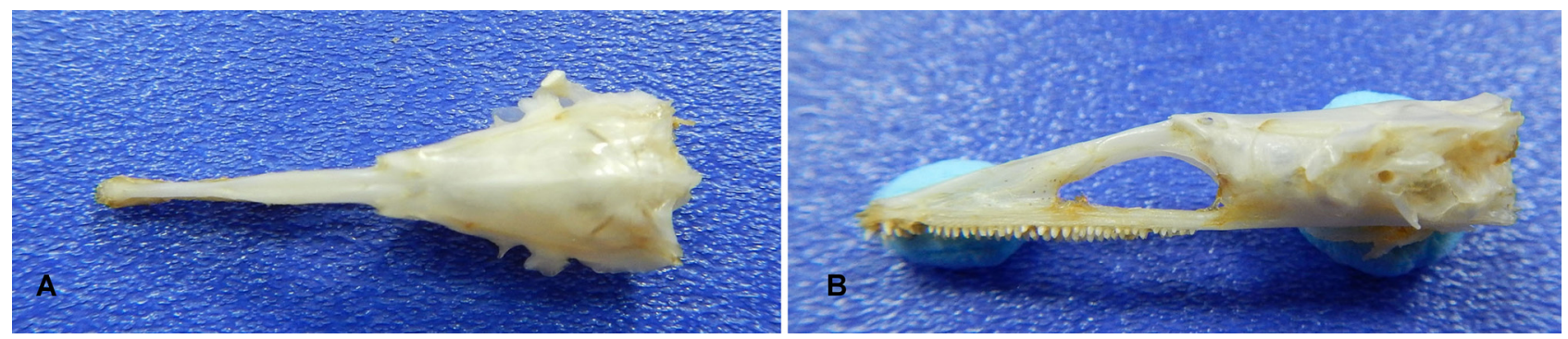

FIGURE 15. Dorsal and left lateral view of Echelus uropterus, TOU-AE 7441, $36.2 \mathrm{~cm}$ TL (A, B).

\subsection{Ophichthus bicolor McCosker \& Ho, 2015}

(Fig. 16 A-B)

Specimens examined and length measurements: One sample. TOU-AE 7345, $35.4 \mathrm{~cm}$ in TL. NCL: $39.41 \mathrm{~mm}$; NCW: $12.36 \mathrm{~mm}$; OBL: $10.62 \mathrm{~mm}$; PEVW: $2.91 \mathrm{~mm}$; MFW: $5.89 \mathrm{~mm}$; NCDB: $7.77 \mathrm{~mm}$; and mPOBD: $4.4 \mathrm{~mm}$.

Diagnosis: The PEV plate is small and elongated. Ethmoid thin and long, a pore is present at the posterior end. The frontals are fused. The orbit space is wide and displays semi-oblong in shape. Basisphenoid has a medial process directed towards the orbit. The sphenotics are broad and directed downwards, aligned with the ventral flange of pterotics. The pterosphenoid is compact and smooth. The paired parietals and epiotics have angled lines visible from the inside of the cranium. Supraoccipital ascends dorsally surpassing the proximal end of epiotics and pterotics. The basioccipital has a ventrally protruding base.

\subsection{Ophichthus erabo (Jordan \& Snyder, 1901)}

(Fig. 16 C-D)

Specimens examined and length measurements: One sample. TOU-AE 7641, $82.5 \mathrm{~cm}$ in TL. NCL: $34.23 \mathrm{~mm}$; NCW: $14.07 \mathrm{~mm}$; OBL: $7.84 \mathrm{~mm}$; PEVW: $3.45 \mathrm{~mm}$; MFW: $6.87 \mathrm{~mm}$; NCDB: $8.19 \mathrm{~mm}$; and mPOBD: $4.8 \mathrm{~mm}$.

Diagnosis: The PEV plate is small and elongated. Ethmoid thin and long. The frontals are fused; a paired pore is present at the anterior end. The orbit space is wide but slightly compress in the anterior end, it displays semi-oblong in shape. Basisphenoid has a medial process directed towards the orbit. The sphenotics are broad and directed sideways, aligned with the ventral flange of pterotics. The pterosphenoid is compact and has a slightly rough surface. Supraoccipital ascends dorsally surpassing the proximal end of epiotics and pterotics. The basioccipital has a ventrally protruding base.

\subsection{Ophichthus urolophus (Temminck \& Schlegel, 1846)}

(Fig. 16 E-F)

Specimens examined and length measurements: Four samples. TOU-AE 7299, $56.3 \mathrm{~cm}$; TOU-AE 7309, 54.7 
cm; TOU-AE 7638, $38.0 \mathrm{~cm}$; TOU-AE 7639, $36.6 \mathrm{~cm}$; all in TL. NCL: 22.59-32.9 mm; NCW: 7.8-13.14 mm; OBL: 6.31-8.31 mm; PEVW: 1.82-3.65 mm; MFW: 2.86-4.72 mm; NCDB: 4.73-7.57 mm; and mPOBD: 2.82$3.84 \mathrm{~mm}$.

Diagnosis: The PEV plate is small and elongated. Ethmoid thin and long and has a shallow crease in the middle. The frontals are fused; a paired pore is present at the anterior end. The orbit space is wide and displays semi-oblong in shape. Basisphenoid has a medial process directed towards the orbit. The sphenotics are broad and descend downwards, aligned with the ventral flange of pterotics. The pterosphenoid is compact and smooth. Supraoccipital ascends dorsally surpassing the proximal end of epiotics and pterotics. The basioccipital has a pointed base.

\subsection{Ophisurus macrorhynchos Bleeker, 1852b}

(Fig. $16 \mathrm{G}-\mathrm{H})$

Specimens examined and length measurements: One sample. TOU-AE 5092, $185.2 \mathrm{~cm}$ in TL. NCL: $88.67 \mathrm{~mm}$; NCW: $18.40 \mathrm{~mm}$; OBL: $32.28 \mathrm{~mm}$; PEVW: $4.21 \mathrm{~mm}$; MFW: $4.3 \mathrm{~mm}$; NCDB: $4.74 \mathrm{~mm}$; and mPOBD: $10.17 \mathrm{~mm}$.

Diagnosis: The PEV plate is small and elongated. Ethmoid thin and long and has a shallow crease in the middle. The frontals are fused; a pore is present near the anterior end. The parietals have ridge at the midline. The orbit space is wide and displays semi-oblong in shape. Basisphenoid has a medial process directed towards the orbit. The sphenotics are broad and extends sidewards, longer than the ventral flange of pterotics. The pterosphenoid is compact and smooth. Supraoccipital ascends dorsally but ends before the proximal margin of epiotics and pterotics.

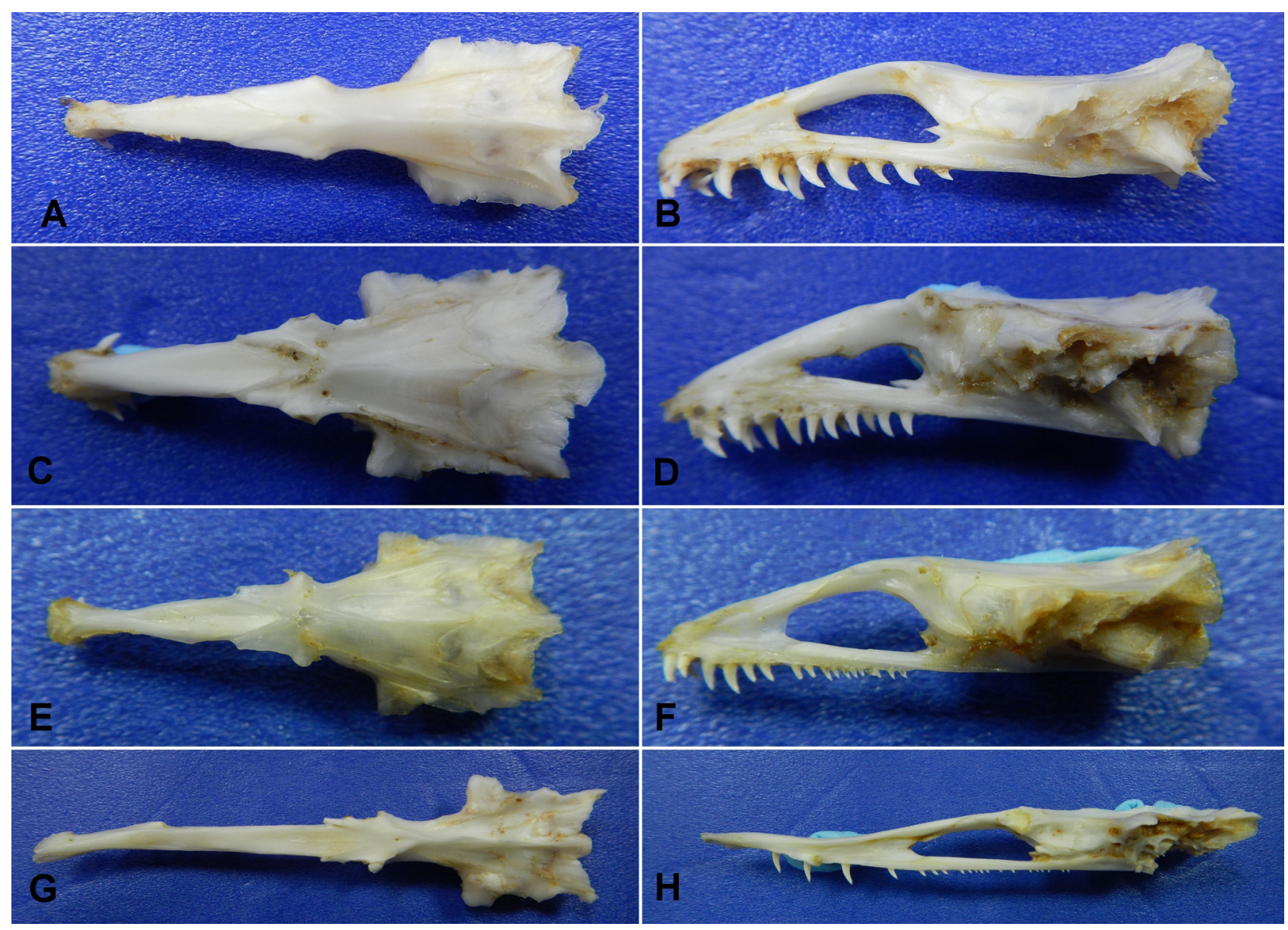

FIGURE 16. Dorsal and left lateral view of Ophichthus bicolor, TOU-AE 7345, $35.4 \mathrm{~cm}$ TL (A, B); O. erabo, TOU-AE 7641, $82.5 \mathrm{~cm}$ in TL (C, D); O. urolophus, TOU-AE 7299, $56.3 \mathrm{~cm}$ TL (E, F); and Ophisurus macrorhynchus. TOU-AE 5092, 185.2 $\mathrm{cm}$ TL $(\mathrm{G}, \mathrm{H})$. 


\section{Family Synaphobranchidae}

\subsection{Dysomma anguillare Barnard, 1923}

(Fig. 17 A-B)

Specimens examined and length measurements: Two samples. TOU-AE 7343, $49.5 \mathrm{~cm}$; TOU-AE 7344, 58.6 cm; all in TL. NCL: 30.4_-32.6 mm; NCW: 9.46-13.14 mm; OBL: 5.07-6.54 mm; PEVW: 2.87-3.28 mm; MFW: 4.04-5.58 mm; NCDB: 6.89-8.04 mm; and mPOBD: 3.61-4.61 mm.

Diagnosis: The PEV tip is blunt, dorsally convex, and elongated. Vomer has some pores present at the surface. Frontal has a pair of shallow, slit-like depression at the lateral side of the anterior end. The orbit space is moderately small and partially covered. Basisphenoid extends anteriorly and covers half of the posterior part of the orbit. The sphenotics are slightly reduced. The parietals, supraoccipital, and epiotics are elevated posteriorly. The pterosphenoid is compact and smooth. The basioccipital has a pointed base.

\subsection{Dysomma polycatodon Karrer, 1983}

(Fig. 17 C-D)

Specimens examined and length measurements: One sample. TOU-AE 7346, $46.6 \mathrm{~cm}$ in TL. NCL: $23.19 \mathrm{~mm}$; NCW: 8.99 mm; OBL: 5.46 mm; PEVW: 2.42 mm; MFW: 3.43 mm; NCDB: 5.5 mm; and mPOBD: 3.4 mm.

Diagnosis: The PEV tip is blunt, dorsally convex, and elongated. Vomer has paired pores present at the surface. Frontal has shallow, slit-like depression at the surface of the anterior end. The orbit space is moderately small and partially covered. Basisphenoid extends anteriorly and covers half of the posterior part of the orbit. The sphenotics are short and descend downward. The parietals, supraoccipital, and epiotics are elevated posteriorly. The pterosphenoid is compact and smooth. The basioccipital has a pointed base.
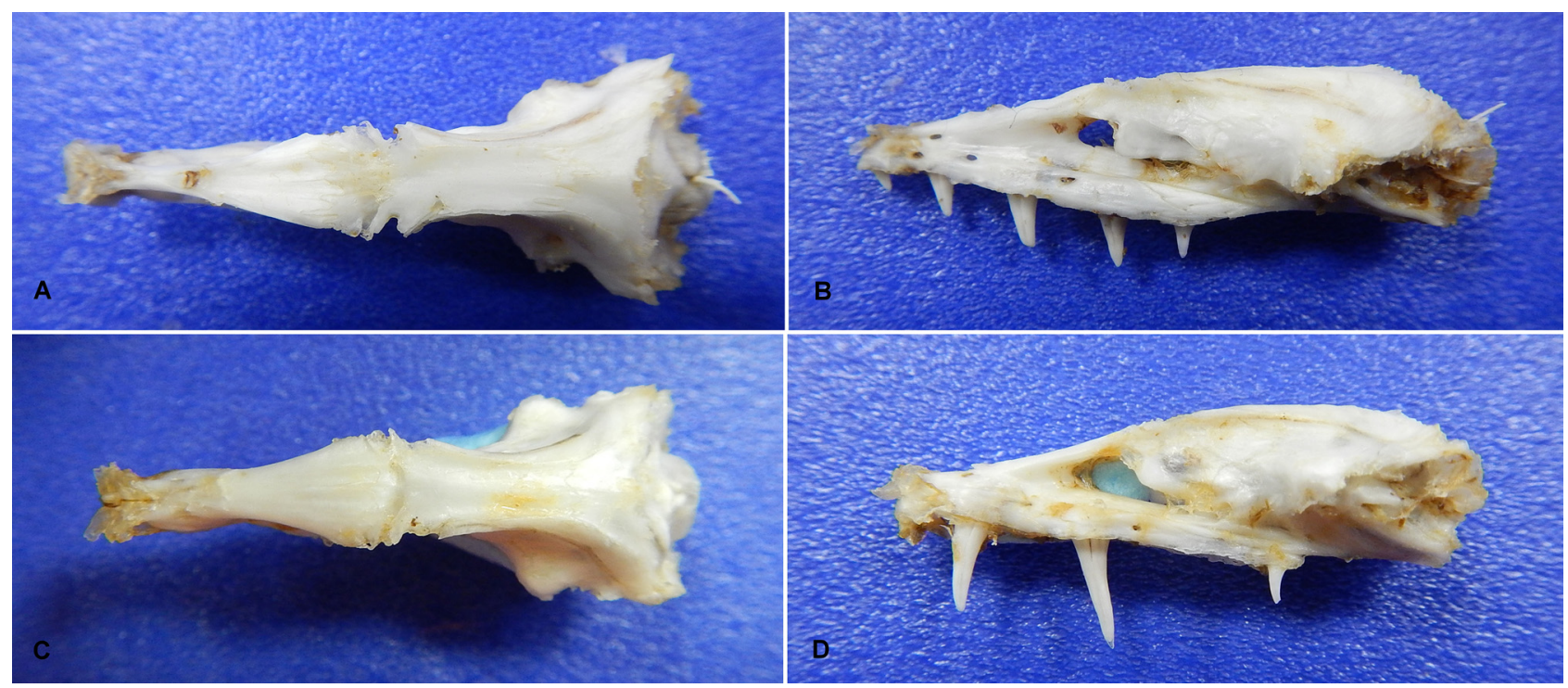

FIGURE 17. Dorsal and left lateral view of Dysomma anguillare TOU-AE 7343, $49.5 \mathrm{~cm}$ TL (A, B); and D. polycatodon, TOU-AE 7346, $46.6 \mathrm{~cm}$ in TL (C, D).

\subsection{Meadia abyssalis (Kamohara, 1938)}

(Fig. $18 \mathrm{~A}-\mathrm{B})$

Specimens examined and length measurements: Two samples. TOU-AE 7325, $51.8 \mathrm{~cm}$; TOU-AE $7336,67 \mathrm{~cm}$; all in TL. NCL: 37.55-51.43 mm; NCW: 9.4-13.63 mm; OBL: 9.58-12.48 mm; PEVW: 3.23-5.26 mm; MFW: 2.62-5.39 mm; NCDB: 6.88-9.7 mm; and mPOBD: 3.11-4.69mm.

Diagnosis: The PEV plate is small and elongated. Ethmoid is thin, long, and has a shallow crease in the 
middle. The frontals are fused; a paired pore is present at the anterior end. The orbit space is wide and displays triangular in shape. Basisphenoid has a medial process directed towards the orbit. The sphenotics are short and the flange is directed sideways. The pterosphenoid is compact and has a smooth surface. Supraoccipital ascends dorsally surpassing the proximal end of epiotics and pterotics. The basioccipital has a ventrally protruding base. Neurocranium has whitish coloration and smooth structure.
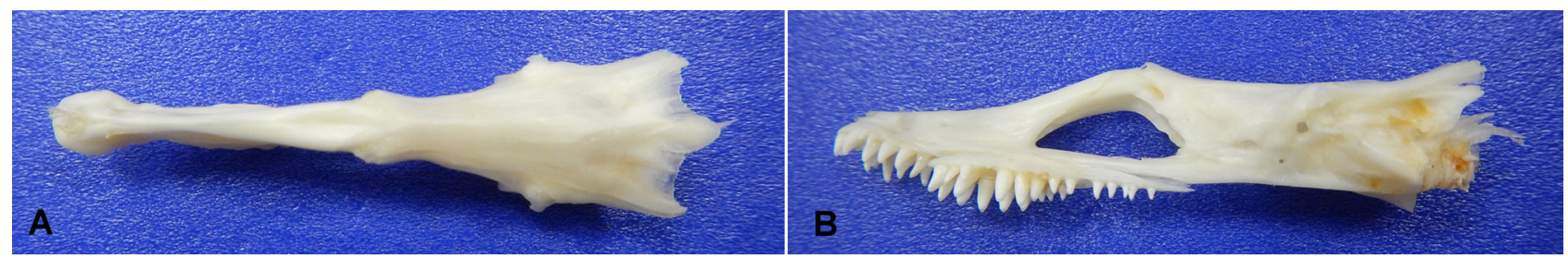

FIGURE 18. Dorsal and left lateral view of Meadia abyssalis. TOU-AE 7325, $51.8 \mathrm{~cm}$ TL (A, B).

\subsection{Synaphobranchus kaupii Johnson, 1862}

(Fig. 19 A-B)

Specimens examined and length measurements: Two samples. TOU-AE 7175, $58.5 \mathrm{~cm}$; TOU-AE 7282, $54.9 \mathrm{~cm}$; all in TL. NCL: 36.55-37.56 mm; NCW: 11.29-11.3 mm; OBL: 14.39-14.62 mm; PEVW: 1.7- $2.37 \mathrm{~mm}$; MFW: 2.25-2.61 mm; NCDB: 6.61-7.98 mm; and mPOBD: 2.54-2.74 mm.

Diagnosis: The PEV plate is small and elongated. Ethmoid is thin and long. The frontals are fused. The orbit space is distinctly wide and displays roughly triangular. The sphenotics are short and descend downward, but longer than the lateral margin of pterotics. The pterosphenoid is compact and has a smooth surface. The supraoccipital and epiotics are elevated posteriorly. The pterotics have a small lateral extension. The basioccipital has a ventrally protruding base. Neurocranium has whitish coloration and thin structure.
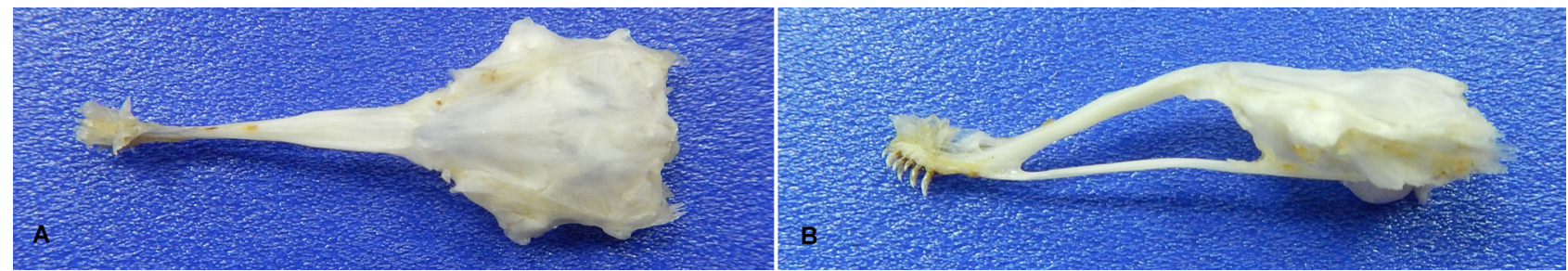

FIGURE 19. Dorsal and left lateral view of Synaphobranchus kaupii TOU-AE 728254.9 cm. TL. (A, B).

The neurocranium of Anguilliformes fishes (Figs. 3-18) is somewhat narrow in the front and broad behind. The premaxilla forms the anterior end, and either the supraoccipital crest and/or pterotic forms the posterior end of the neurocranium. The sides of the neurocranium are not entire but are formed by the slender projections or processes of the frontals, sphenotics, and pterotic bones. On the dorsal side, the ridge in between frontals and/or supraoccipital was arisen posteriorly in a converging manner and forms the outer borders of the neurocranium. The orbital concavity is either small or wide in some species.

On the lateral side of the neurocranium, seven major parts stand out conspicuously, beginning from the anterior end, the premaxilla-ethmovomer, the frontals, the sphenotics, the pterotics, the supraoccipital, the occipital bones, and the parasphenoid. The neurocranium of species under family Congridae resembles closely in sharing small PEV, uneven surface of parietals, and thin posterior margin of surface pterotic region, except for the species Heteroconger hassi that has cylindrical structure and posterior margin shows the elements underneath. Further, the supraoccipital spine is less prominent in this family, whereas the species Parabathymyrus macrophthalmus was unobservable from the surface area. Among the family, Congridae and Ophichthidae resemble more closely between themselves in that the shape of the orbit (Fig. 20), and the thickness of the parasphenoid are similar to each other (Fig. 21). Orbits are large, more than 1/3 length of the neurocranium. Among the seven families, Conger macrocephalus under family Congridae has the greatest measurements of orbit length. The species under family Muraenidae have circular orbital shape, whereas most species in family Congridae have elongated shape except in Parabathymyrus macrophthalmus and Heteroconger hassi. The species Dysomma anguillare, D. polycatodon and Meadia abyssalis were coded for having a circular rather than an elongated orbital shape. 
A

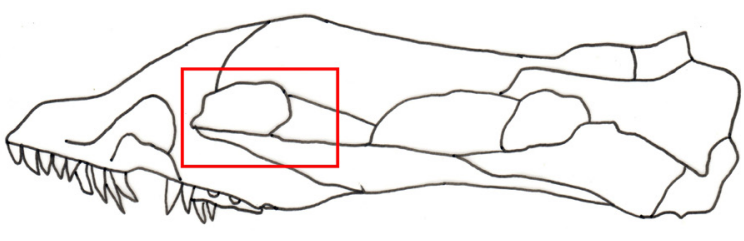

FIGURE 20. Orbit shape. A, circular; B, elongated.

\section{A}

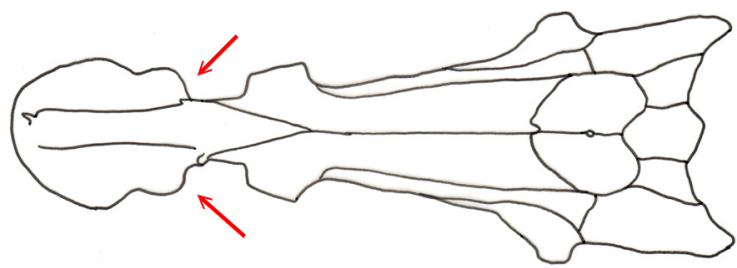

B

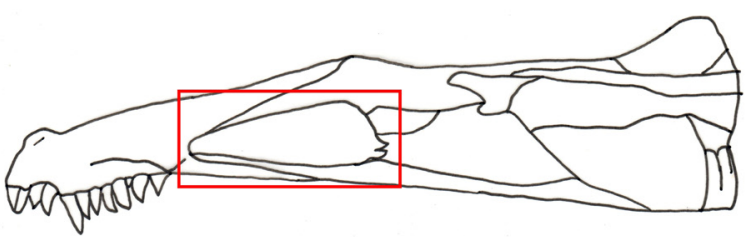

FIGURE 21. Parasphenoid shape. A, thick; B, thin.

A paired extension process at the posterodorsal end of PEV was also recorded and exclusive from the family Congridae. Although in Parabathymyrus macrophthalmus, it was directed toward premaxilla (Fig. 22), which is different from the species under genus Bathycongrus, Conger, and Uroconger (Fig. 23), whereas in Heteroconger hassi, it was absent. Another remarkable to this family is the swollen and formation of a thin-walled bulla in basioccipital (Fig. 24). It was also observed in other species from family Ophichthidae (Echelus uropterus and Ophichthus urolophus) and Synaphobranchidae (Synaphobranchus kaupii), whereas other families have small, thick and slightly protruding basioccipital.

A

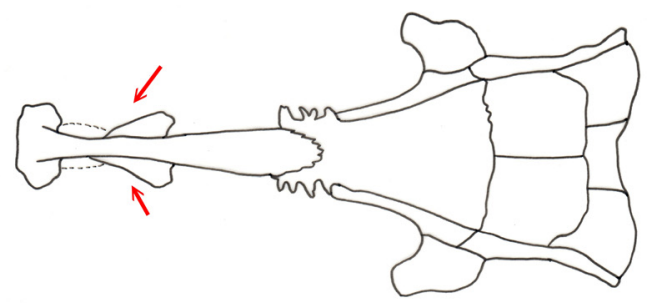

B

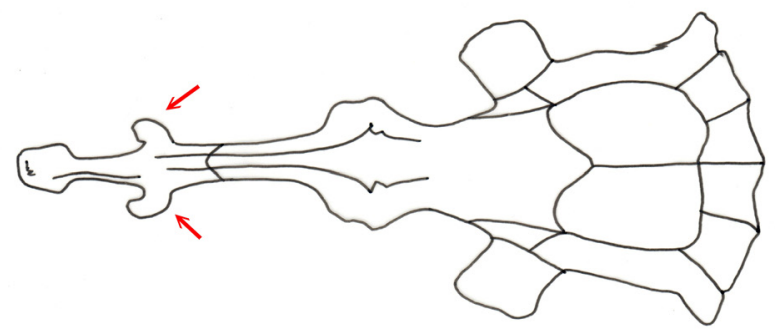

FIGURE 22. Direction of the protrusion at the posterodorsal margin of the premaxilla plate. A, toward posterior; B, toward anterior.

A
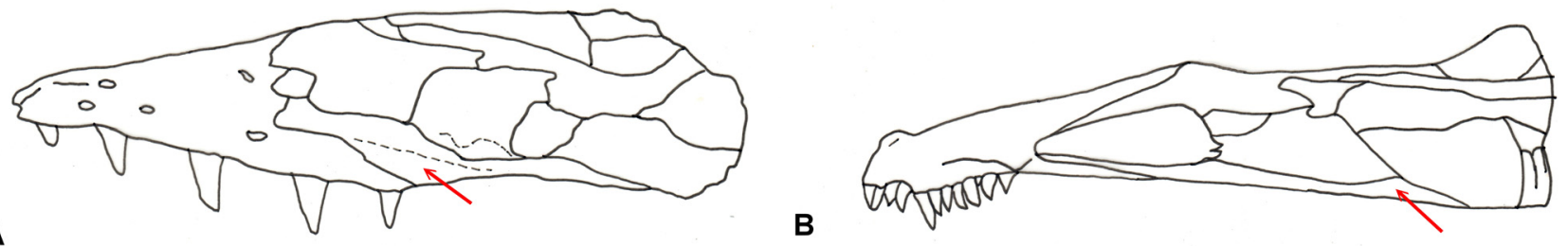

FIGURE 23. Paired extension process at posterodorsal end of PEV. A, absent; B, present.

The family was coded for having a broad or small premaxillary plate size. This is observable on the anterodorsal part of the PEV. The family Muraenidae was recorded to have a broader premaxillary plate than the families Muraenesocidae, Nemichthyidae, Synaphobranchidae, Ophichthidae, and Nettastomatidae (Fig. 25). Furthermore, the depressed surface connection of ethmoid toward premaxilla was also observed from the family Muraenidae, but only for species Uropterygius marmoratus, and U. micropterus. Surprisingly, the species Parabathymyrus macrophthalmus (Congridae) also have this character (Fig. 26). 
A

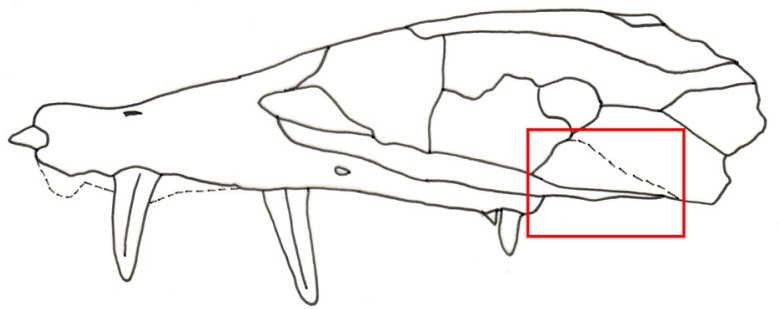

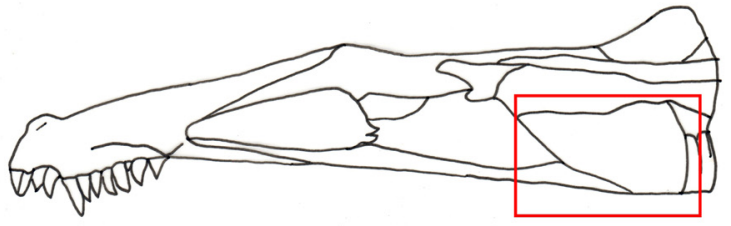

B

FIGURE 24. Swollen and formation of a thin-walled bulla in basioccipital. A, absent; B, present.

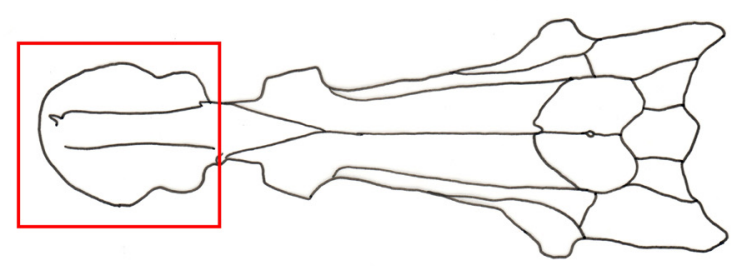

A

FIGURE 25. Premaxillary plate size. A, broad; B, small.

A

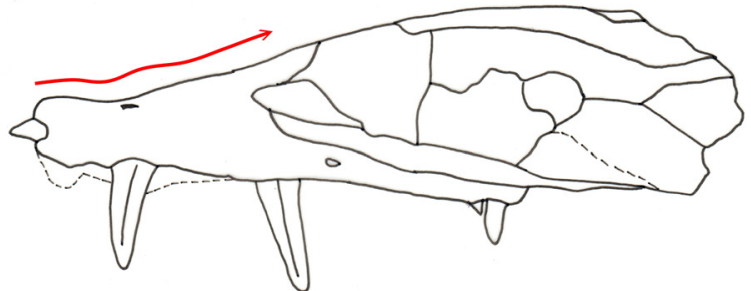

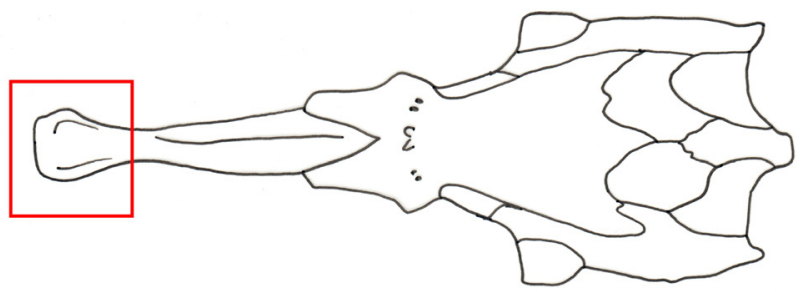

B

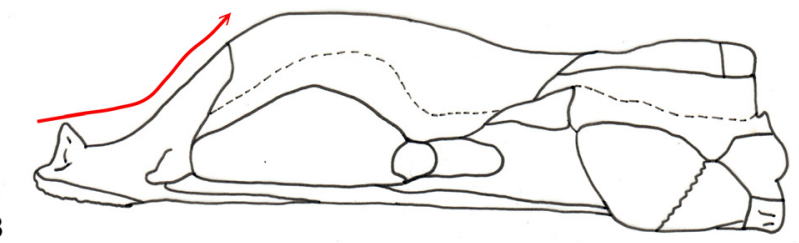

FIGURE 26. Surface connection of ethmoid toward premaxilla. A, no depression; B, has depression.

Anguilliformes fishes have broad frontals and roughly rectangular in shape, among the families, only the family Muraenidae has the paired frontals (Fig. 27). It was joint by either suture or ridge in between the connection and the commissure was extended until the paired parietals. An additional feature on the anterolateral part of the frontal surface is the sideways extension (Fig. 28). Frontals have a small lateral extension of at least three pairs cartilages which is present in family Congridae, except for Heteroconger hassi, whereas in Parabathymyrus macrophthalmus, it was a hard process (Fig. 29). A similar structure of the lateral extension process was also observed in the family Muraenidae, wherein the prolongation was ornamented over the exposed and elevated area of the dorsal part. These sideways extended process from the frontal surface were coded for either thin or thick (Fig. 30). The species Parabathymyrus macrophthalmus was the only species among family Congridae having a thick extended process. The family Muraenidae is distinguishable for having a thick extended process at the frontal, whereas the remaining family was coded thin because of the short cartilage extension.

A

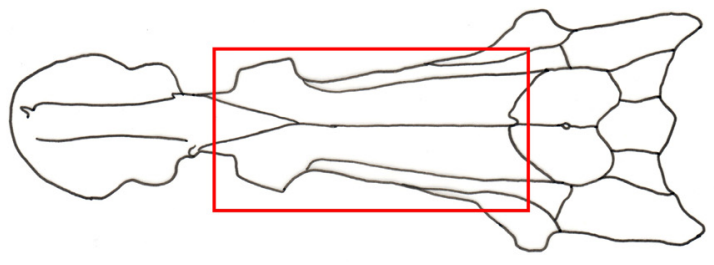

B

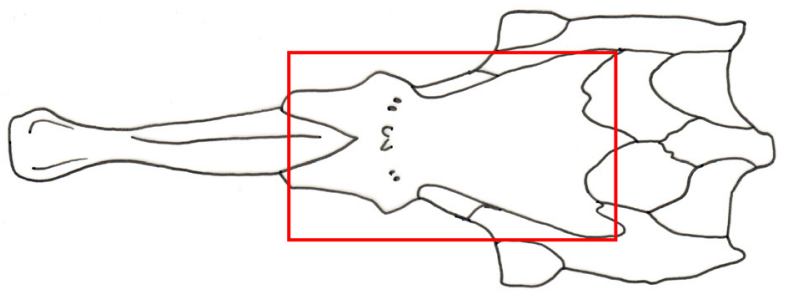

FIGURE 27. Frontals. A, paired; B, fused.

The longitudinal ethmoid was observed to be elongated in most of the species of each family but not the entire, for example in family Ophichthidae, it was recorded short in Ophichthus erabo, and O. urolophus, and the Dysomma anguillare, and D. polycatodon in family Synaphobranchidae (Fig. 31). An additional feature of the ethmoidal crest is the crease in the middle of ethmoid. It is characterized by the presence of shallow longitudinal crease or slightly groove in the middle of the ethmoid which is visible in some species under family Congridae, 
Muraenidae, Ophichthidae and Synaphobranchidae whereas in species Nemichthys scolopaceus (Nemichthyidae), Nettastoma parviceps and N. gephyra (Nettastomatidae), this character is absent (Fig. 32).

A

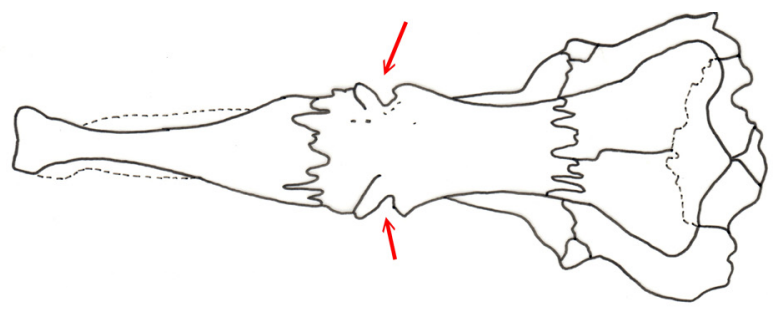

B

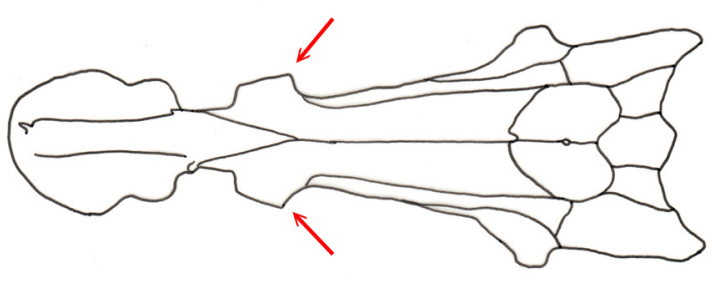

FIGURE 28. Anterolateral part of the frontal surface. A, no extended process; B, has extension.

A

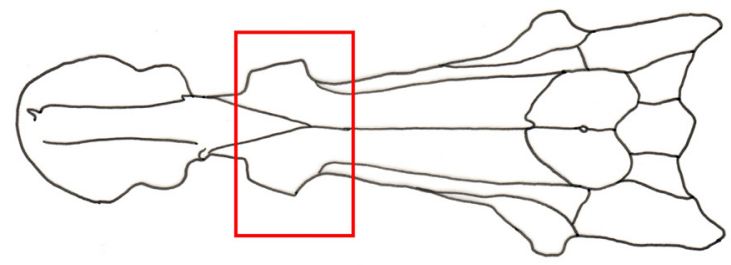

B

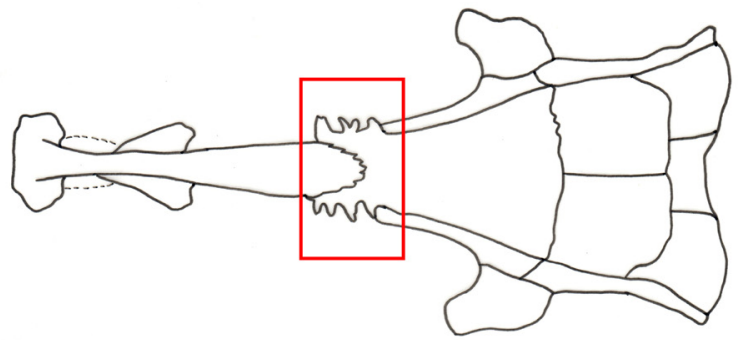

FIGURE 29. Several small lateral extension of paired cartilages attached from the anterior surface of frontal. A, absent; B, present.

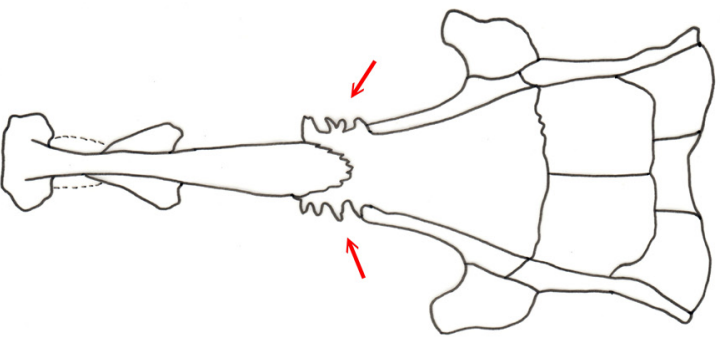

B

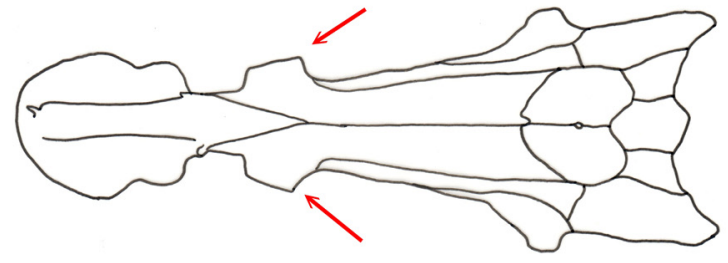

FIGURE 30. Sideways extended process from frontal surface. A, thin; B, thick.

A

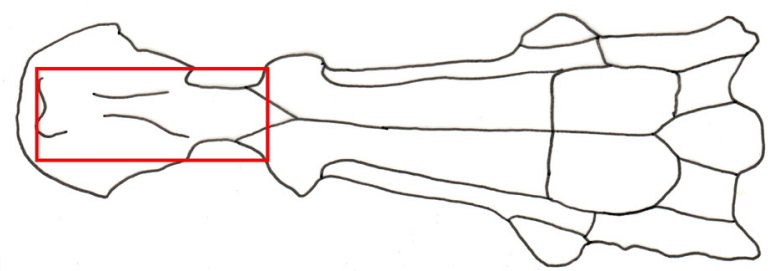

FIGURE 31. Longitudinal ethmoid shape. A, short; B, elongated.

A

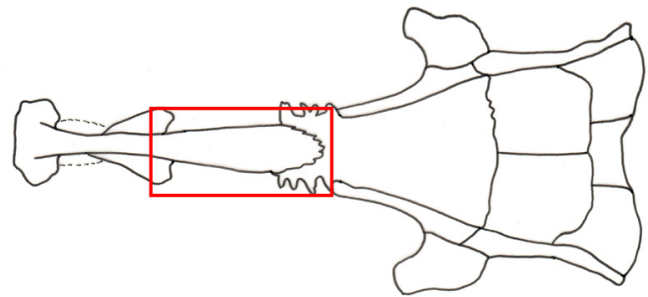

B

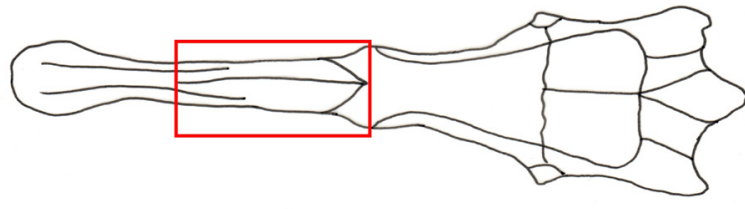

FIGURE 32. Crease in the middle of ethmoid. A, absent; B, present.

On the lateral side of the neurocranium, the sphenotic which is a small paired bone attached to the outer surface of the pterosphenoid were characterized in the direction of sphenotic flanges of either downwards and/or sideways, or toward PEV (Fig. 33). The species in family Muraenidae and Synaphobranchidae were coded for having downwards and/or sideways sphenotic flanges, whereas the rest of the species in the five families have sphenotic flanges directed 
toward PEV. In family Synaphobranchidae, the sphenotic size is small and has blunt edges, this was also observed in some species under family Muraenidae. The families Congridae (except in Parabathymyrus macrophthalmus), Nemichthyidae, Nettastomatidae, Ophichthidae, and Synaphobranchidae have moderate to long sphenotic size. The sphenotics are long and narrow in the dorsal aspect, and a roughly triangular flange extends laterally from each sphenotic (Fig. 34). A blunt sphenotic edge was observed in family Muraenidae, Nettastomatidae, Ophichthidae, and Synaphobranchidae, whereas the species Nemichthys scolopaceus were recorded in having a pointed sphenotic edge. In the family Congridae, most of the species have pointed sphenotic edge except for Uroconger lepturus and Heteroconger hassi, the latter being resembled more in morays (Fig. 35).

A
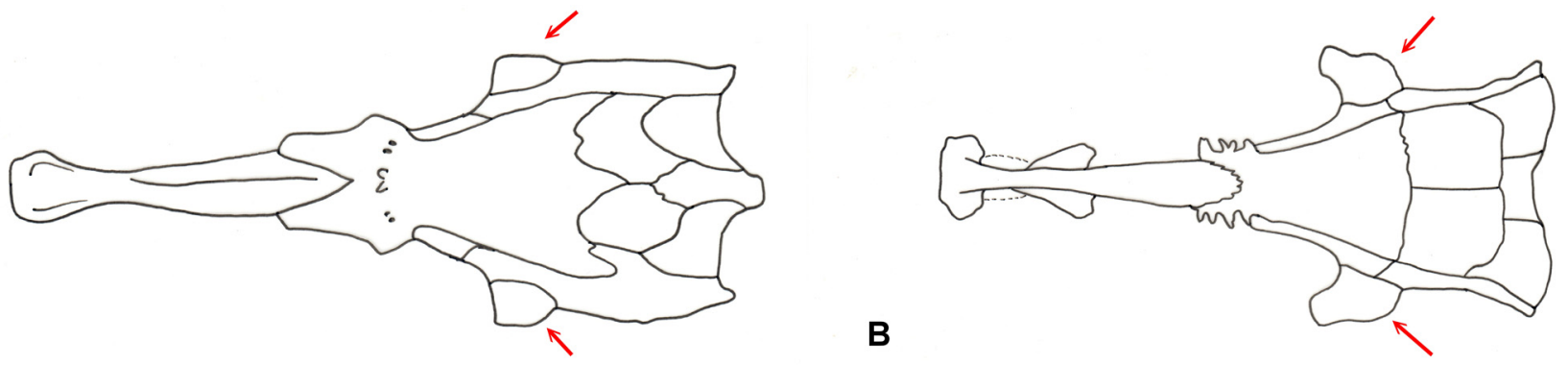

FIGURE 33. Direction of sphenotic flanges. A, downwards or sideways; B toward PEV.

A

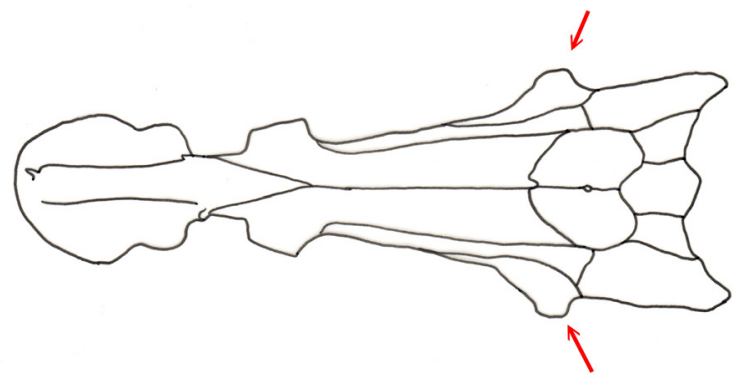

FIGURE 34. Sphenotic size. A, small; B moderate to long.

A

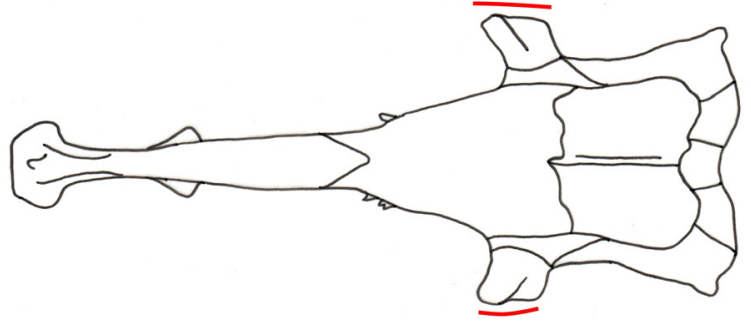

FIGURE 35. Type of sphenotic edge. A, blunt end; B, pointed.

The posterodorsal part of neurocranium was assessed on the prolongation of supraoccipital of either anterior or posterior over pterotic proximal end (Fig. 36). In Congridae, it was observed in Conger cinereus, C. macrocephalus, and Parabathymyrus macrophthalmus, that the supraoccipital ends anterior to pterotic, whereas the remaining species under this family have supraoccipital ends posterior to pterotic. Muraenesox cinereus and species under Nemichthyidae, Nettastomatidae, and Ophichthidae were recorded in having supraoccipital ends posterior to pterotic whereas in family Muraenidae and Synaphobranchidae were not entirely similar in this character. Additional character is the projection of supraoccipital median crest. In some species within the family, it is ascending outward, whereas most of the species have greatly reduced supraoccipital. In family Muraenesocidae, Muraenesox cinereus displayed and ascending outward supraoccipital, same with the species under family Ophichthidae. The family Congridae, Nemichthyidae, and Nettastomatidae have greatly reduced supraoccipital median crest whereas species under family Muraenidae and Synaphobranchidae were not entirely similar in this character. Moreover, the supraoccipital of Parabathymyrus macrophthalmus was unobservable due to the overlapping epiotics on the dorsal part, and was therefore characterized as greatly reduced (Fig. 37). 

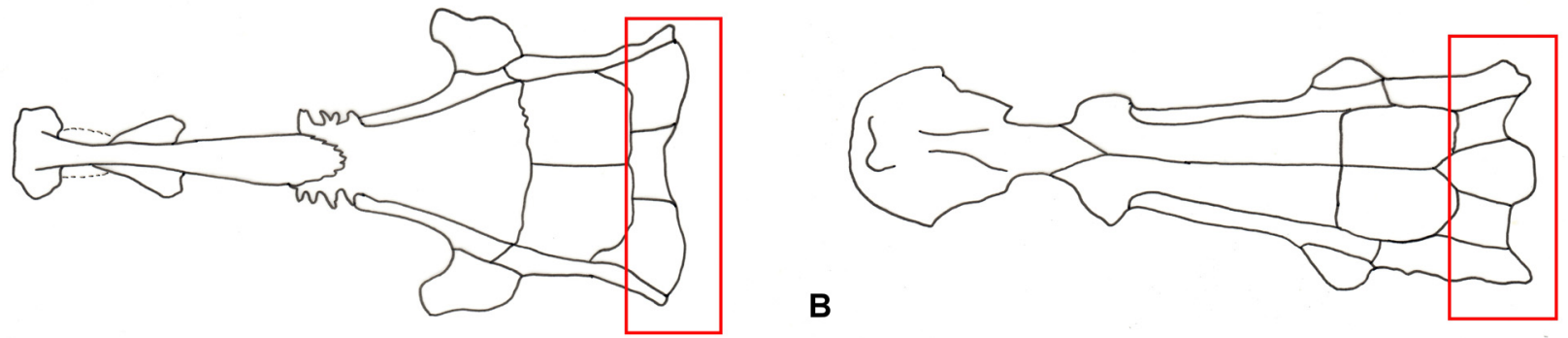

FIGURE 36. Prolongation of supraoccipital over pterotic. A, anterior; B posterior.

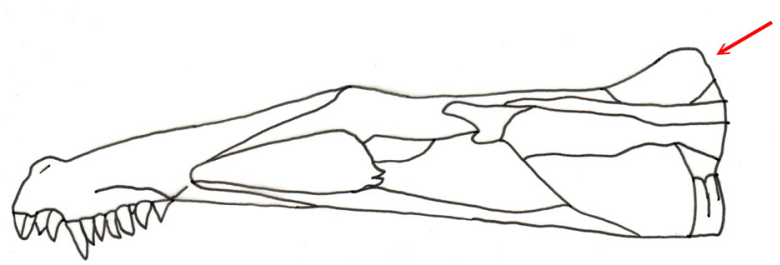

A

FIGURE 37. Projection of supraoccipital median crest. A, ascend outward; B, greatly reduced.

The coverage of vomerine teeth in different families was also coded. It was noted that family Congridae, Muraenesocidae, Nemichthyidae, and Nettastomatidae have vomerine teeth that ends before the anterior margin of orbit. A similar observation in species in Echelus uropterus, Ophichthus erabo, O. urolophus, Meadia abyssalis, and Synaphobranchus kaupii, whereas the remaining species have vomerine teeth that extends beyond anterior or even posterior margin of orbit (Fig. 38).

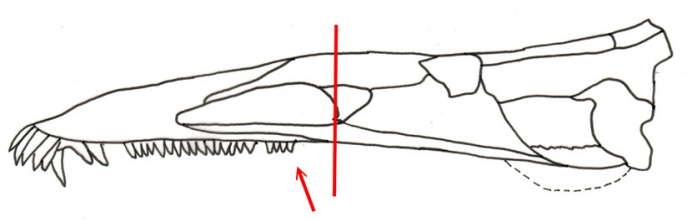

A

FIGURE 38. Coverage of vomerine teeth to the margin of orbit. A, ends before anterior margin of orbit; B, extend beyond anterior margin of orbit.

The parasphenoid is median and elongated bone situated at the base of the neurocranium. It is connected to the basisphenoid, is a long shaft of a bone that extends from the posterior end of vomer to the basioccipital. In the lower surface of the bone under the area of the orbital region, the family Congridae, Muraenesocidae, and Nettastomatidae, was observed to have a thin structure (Fig. 21), whereas it is thick in the family Muraenidae with the exemption in Rhinomuraena quaesita which displays thin parasphenoid. Some species in family Ophichthidae (Ophichthus bicolor and O. erabo), and Synaphobranchidae (Dysomma anguillare, D. polycatodon, and Meadia abyssalis) have a thick structure of parasphenoid.

Another remarkable character in Anguilliformes fishes is the extended sharp process at the basisphenoid (Fig. 39). In family Congridae (except for Parabathymyrus macrophthalmus), Muraenesocidae, Nemichthyidae, Nettastomatidae, and Synaphobranchidae, this character is absent, whereas in Muraenesox cinereus under family Muraenesocidae, an extended sharp process right under the opening of the brain was recorded. This is similar in some species of family Muraenidae (e.g., Gymnothorax niphostigmus, G. rueppelliae, G. shaoi, G. taiwanensis, and Rhinomuraena quaesita), and Ophichthidae (Ophichthus bicolor, O. erabo, and O. urolophus).

These 20 morphological characters from seven families of Anguilliformes fishes based on the description of neurocranium morphology used were summarized. The family Congridae was distinguished by having paired extension process at posterodorsal end of PEV; small premaxillary plate size; fused frontals; elongated longitudinal ethmoid; prolongation of sphenotic flanges directed toward PEV; vomerine teeth extend beyond margin of orbit; thin parasphenoid; and ascending outward projection of supraoccipital median crest. 


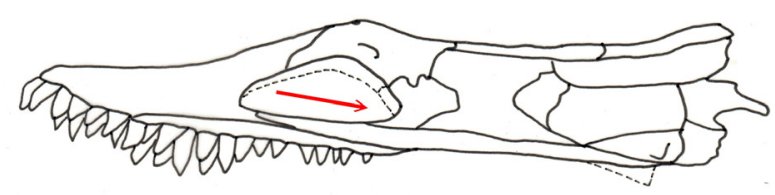

B

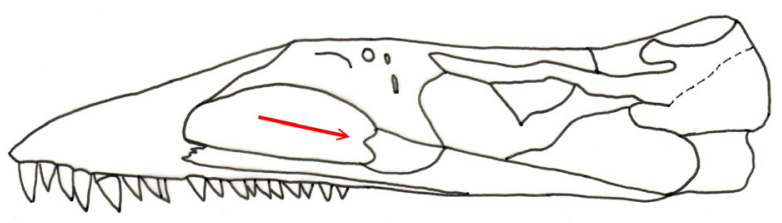

FIGURE 39. Extended sharp process at the basisphenoid. A, absent; B present.

The family Muraenidae have similar morphological characters in having absence of paired extension process at posterodorsal end of PEV; not swollen or no formation of a thin-walled bulla in basioccipital; broad premaxillary plate size; paired frontals; absence of extension on the anterolateral part of the frontal surface; a thin sideways extended process from frontal surface; the protrusion at the posterodorsal margin of the premaxilla plate which is directed posteriorly; circular orbit shape; absence of several small lateral extension of paired cartilages from the anterior surface of frontal; a downwards or sideways direction of sphenotic flanges; a blunt end sphenotic edge; and vomerine teeth extend beyond anterior margin of orbit. Within the family Muraenidae, the species of subfamily Uropterygiinae have the lowest measurements on mid pre-orbital depth which resulted in the highest values on the relative ratio of the NCW to $\mathrm{mPOBD}$ ranging from 2.33-3.12. The unique characters were observed on having the lowest value on the depth of mid pre-orbit due to the termination of the ethmoidal crest toward premaxilla.

The species in family Ophichthidae were distinguished by having absence of paired extension process at posterodorsal end of PEV; small premaxillary plate size; no depression on the surface connection of ethmoid toward premaxilla; fused frontals; anterolateral part of the frontal surface has extension; a thin sideways extended process from frontal surface; the protrusion at the posterodorsal margin of the premaxilla plate which is directed posteriorly; an elongated orbit shape; absence of several small lateral extension of paired cartilages attached from the anterior surface of frontal; moderate to long sphenotic size; the prolongation of supraoccipital posterior to that of pterotic; a blunt end sphenotic edge.

The family Synaphobranchidae was distinguished from the other families by the absence of paired extension process at posterodorsal end of PEV; small premaxillary plate size; no depression on the surface connection of ethmoid toward premaxilla; fused frontals; absence of extension on the anterolateral part of the frontal surface; a thin sideways extended process from frontal surface; the protrusion at the posterodorsal margin of the premaxilla plate which is directed posteriorly; absence of several small lateral extension of paired cartilages attached from the anterior surface of frontal; a downwards or sideways direction of sphenotic flanges; a small sphenotic size; a blunt end sphenotic edge; and the absence of extended sharp process at the basisphenoid.

The species in family Nettastomatidae were distinguished by having all the characters except for the extension on the anterolateral part of the frontal surface. It is present in Nettastoma parviceps whereas no extension observed in Nettenchelys gephyra.

The species under the order Anguilliformes differ in the structure of premaxilla-ethmovomer, frontals, basioccipital, sphenotic, parasphenoid, supraoccipital, and orbital shape. Table 1 shows the relative ratio of each species. The relative ratio from each family was listed from greatest to lowest value as follows:

In NCL/NCW: the greatest to least value was recorded from Nemichthys scolopaceus $(12.86)>$ Nettastoma parviceps (4.95) > Ophisurus macrorhynchus (4.82) > Rhinomuraena quaesita (4.75) > Muraenesox cinereus (4.31) > Meadia abyssalis (3.88) > Conger macrocephalus (3.73); in NCL/OBL: Uropterygius micropterus (8.38) $>$ Nemichthys scolopaceus $(7.76)>$ Conger myriaster $(6.31)>$ Dysomma anguillare (5.49) $>$ Ophichthus erabo (4.37) > Nettastoma parviceps (3.68) > Muraenesox cinereus (3.53); in NCL/MFW: Nettenchelys gephyra $(28.75)>$ Nemichthys scolopaceus $(21.8)>$ Ophisurus macrorhynchus $(18.71)>$ Conger macrocephalus $(15.42)>$ Synaphobranchus kaupii (15.35) > Muraenesox cinereus (10.1) > Rhinomuraena quaesita (6.46); in NCL/NCDB: Nemichthys scolopaceus (12.71) > Nettastoma parviceps (11.31)> Ophisurus macrorhynchus (8.72) > Bathycongrus albimarginatus (7.63) $>$ Rhinomuraena quaesita (6.73) > Muraenesox cinereus (5.92) > Meadia abyssalis (5.38); in NCW/PEVW: Nettastoma parviceps (7.54) $>$ Echelus uropterus (7.06) $>$ Parabathymyrus macrophthalmus (6.25) $>$ Synaphobranchus kaupii (5.7) > Nemichthys scolopaceus (3.61) > Muraenesox cinereus (2.78) > Rhinomuraena quaesita (2.18); in NCW/mPOBD: Nettenchelys gephyra (7.79) > Bathycongrus guttulatus (5.06) > Uropterygius marmoratus (4.99) > Nemichthys scolopaceus (4.65) > Ophisurus macrorhynchus (4.37) > Synaphobranchus kaupii (4.28) > Muraenesox cinereus (2.29); in PEVW/mPOBD: Uropterygius marmoratus (3.12) > Nettenchelys 
gephyra (2.32) > Conger myriaster $(1.81)>$ Nemichthys scolopaceus $(1.29)>$ Meadia abyssalis $(1.08)>$ Ophisurus macrorhynchus (1.02) > Muraenesox cinereus (0.83); in NCW/MFW: Nettenchelys gephyra (7.72) > Bathycongrus guttulatus (4.75) > Synaphobranchus kaupii (4.67) > Echelus uropterus (4.56) > Muraenesox cinereus (2.35) > Uropterygius marmoratus (1.82) > Nemichthys scolopaceus (1.69); and in OBL/PEVW: Nettastoma parviceps (10.15) > Synaphobranchus kaupii (7.34) > Nemichthys scolopaceus (5.99) > Echelus uropterus (5.47) > Parabathymyrus macrophthalmus (5.24) > Muraenesox cinereus (3.39) > Rhinomuraena quaesita (1.86).

\section{Discussion}

The research in the Anguilliformes fishes in Taiwanese waters revealed a considerable number of differences in terms of neurocranium morphological characters. In previous reports, the observation on the morphological character of having a fused or paired frontals was considered a derived character in Anguilliformes (Belouze, 2001; Eagderi \& Adriaens, 2014). Some characters not indicated by the previous researches may be because of ignoring them. In this study, it was noted that premaxilla plate shape and size also differs among the families. Lack of a lateral ethmoid process is usually observed in those congrids (Robins \& Robins, 1971). Furthermore, it is mostly small in six families whereas mostly extended sideways in the family Muraenidae. Previous studies focused only on the fusion of the premaxillaries with the ethmoid and vomer to form the premaxilla-ethmovomeral complex and termed as a unique attribute among the Anguilliformes (Robins, 1989; Eagderi \& Adriaens, 2014). This character of having a broad premaxilla plate in family Muraenidae may be attributed to their way of feeding as previous researchers refer to them as suction feeders (Mehta \& Wainwright, 2007; Mehta, 2009).

In the families Muraenidae, Nettastomatidae and species Nemichthys scolopaceus, the basioccipital contributes to form the posterior part of the less protruding otic bullae along with the exoccipital and prootic, whereas the species Muraenesox cinereus and most of the species in families Congridae, Ophichthidae and Synaphobranchidae formed a well-developed tumescent bulla. This character may correspond to a larger size of otolith (Chulin \& Chen, 2013). In other fishes, the growth of the otolith is known to be influenced by various factors such as seasonal variations, temperature, habitat and diet (Stransky, 2005; Tuset et al., 2010; Homayuni et al., 2013).

Our hypothesis based on the morphological characters within order Anguilliformes is comparable in general outlines to those of Santini et al. (2013), in the separation of family Muraenidae from the six families. Furthermore, this differences in our results support those based on molecular data (Loh et al., 2008; Reece et al., 2010; Tang \& Fielitz, 2013), in identifying the two sister lineages in Muraenidae. Recent studies on neurocranium morphology of family Muraenidae shows important key to its subfamilies in having significant differences on the measurement of the orbit length and depth of pre-orbit due to the termination of the ethmoidal crest toward premaxilla (RamosCastro et al., 2020).

Previous studies in Anguilliform fishes resulted in separation of family Congridae and Ophichthidae which cannot be supported as monophyletic or sister groups (Wang et al., 2003). In this result, the family Congridae shows significant similarity with families Nettastomatidae, Nemichthyidae, Synaphobranchidae and Ophichthidae in having fused frontals and least premaxillary plate size, and may support the previous phylogenetic studies, which further states that these Anguilliform groups were paraphyletic (Wang et al., 2003; Lopez \& Westneat, 2007; Inoue et al., 2010). For the representative species of family Muraenesocidae, Muraenesox cinereus, based on the morphological characters, the characters showed that it is closely related to family Ophichthidae, as found by Inoue et al. (2010). However, in the basis of relative ratios (Table 1), it is somewhat closer to the species under family Synaphobranchidae. Moreover, the relative ratios obtained from measuring neurocranial elements can differentiate the families under order Anguilliformes. This resulted in recording of family Nettastomatidae closer with the representative species Nemichthyidae, Nemichthys scolopaceus in having an extended length of premaxilla which made the highest measurement in NCL, and the highest value on the ratio of NCL/MFW and NCL/NCDB.

\section{Conclusion}

Osteological characters play a very important role in the classification of different families. The neurocranium of seven families were examined, described, and figured to evaluate the order Anguilliformes. These data can serve 
as a basis for future investigation of neurocranial morphometrics in eels. Based on this study, some important characters, specifically on the neurocranium, differentiated Anguilliformes fishes at the family level. There is a need for further study and inclusion of more characters from other skeletal parts to differentiate these species. Future phylogenetic studies on Anguilliformes fishes will greatly contribute to understanding the morphological diversity underlying these families.

\section{References}

Arai, T., Chin, T.C., Kwong, K.O. \& Azizah, M.N.S. (2015) Occurrence of the tropical eels Anguilla bengalensis bengalensis and Anguilla bicolor bicolor in Peninsular Malaysia and implications for eel taxonomy. Marine Biodiversity Records, 8 , e28. [published online] https://doi.org/10.1017/S1755267215000056

Asano, H. (1962) Studies on the congrid eels of Japan. Bulletin of the Misaki Marine Biological Institute, Kyoto University, 1 , $1-143$.

Barnard, K.H. (1923) Diagnoses of new species of marine fishes from South African waters. Annals of the South African Museum, 13 (14), 439-445.

Belouze, A. (2001) Comprehension morphologique et phylogenetique des taxons actuels et fossiles rapportes aux anguilliformes (Poissons, Teleosteens). Documents des laboratoires de géologie Lyon. No 158. Doctoral dissertation, Université ClaudeBernard Lyon 1, U.F.R. des sciences de la terre, Villeurbanne, $401 \mathrm{pp}$.

Bleeker, P. (1852a) Bijdrage tot de kennis der ichthijologische fauna van de Moluksche Eilanden. Visschen van Amboina en Ceram. Natuurkundig Tijdschrift voor Nederlandsch Indië, 3 (2), 229-309.

Bleeker, P. (1852b) Bijdrage tot de kennis der Muraenoïden en Symbranchoïden van den Indischen Archipel. Verhandelingen van het Bataviaasch Genootschap van Kunsten en Wetenschappen, 25 (5), 1-76.

Böhlke, E.B. (1982) Vertebral formulae for type specimens of eels (Pisces: Anguilliformes). Proceedings of the Academy of Natural Sciences of Philadelphia, 134, 31-49.

Böhlke, E.B., McCosker J.E. \& Böhlke, J.E. (1989) Family Muraenidae. In: Böhlke, E.B. (Ed.), Fishes of the Western North Atlantic. Memoirs of the Sears Foundation for Marine Research. Vol. 1. Part 9. Sears Foundation for Marine Research, New Haven, Connecticut, pp. 104-206.

Brevoort, J.C. (1856) Notes on some figures of Japanese fish taken from recent specimens by the artists of the U. S. Japan Expedition. In: Perry, M.C., Narrative of the Expedition of an American Squadron to the China Seas and Japan, performed in the years 1852, 1853, and 1854 under the command of Commodore M. C. Perry, United States Navy, by order of the Government of the United States, 2, 253-288.

Castle, P.H.J. (1968) The congrid eels of the western Indian Ocean and the Red Sea. Ichthyological Bulletin, Department of Ichthyology, Rhodes University, 33, 685-726.

Castle, P.H.J. \& Smith, D.G. (1981) A revision of nettastomatid eel genera Nettastoma and Netttenchelys (Pisces: Anguilliformes), with descriptions of six new species. In: Smith, D.G., Böhlke, J.E. \& Castle P.H.J., Proceedings of the Biological Society of Washington, 94 (2), 535-560.

Chen, H.-M. \& Loh, K.-H. (2007) Gymnothorax shaoi, a new species of moray eel (Anguilliformes: Muraenidae) from southeastern Taiwan. Journal of Marine Science and Technology, 15 (2), 76-81.

Chen, H.-M., Loh, K.-H. \& Shao, K.-T. (2008) A new species of moray eel, Gymnothorax taiwanensis, (Anguilliformes: Muraenidae) from eastern Taiwan. Raffles Bulletin of Zoology, 19, 131-134.

Chen, H.-M., Shao, K.-T. \& Chen, C.-T. (1996) A new moray eel, Gymnothorax niphostigmus, (Anguilliformes: Muraenidae) from northern and eastern Taiwan. Zoological Studies, 35 (1), 20-24.

Chulin, A.K. \& Chen, H.-M. (2013) Comparative morphological study of otoliths in Taiwanese Anguilliformes fishes. Journal of Marine Science and Technology, 21, 77-85.

De Schepper, N., Adriaens, D. \& De Kegel, B. (2005) Moringua edwardsi (Moringuidae: Anguilliformes): Cranial specialization for head-first burrowing? Journal of Morphology, 266 (3), 356-368. https://doi.org/10.1002/jmor.10383

De Schepper, N., De Kegel, B. \& Adriaens, D. (2007) Pisodonophis boro (Ophichthidae: Anguilliformes): Specialization for head-first and tail-first burrowing? Journal of Morphology, 268 (2), 112-126. https://doi.org/10.1002/jmor.10507

Eagderi, S. \& Adriaens, D. (2014) Cephalic morphology of Ariosoma gilberti (Bathymyrinae: Congridae). Iranian Journal of Ichthyology, 1 (1), 39-50.

Ege, V. (1939) A revision of the genus Anguilla Shaw. Dana Rep, 16, 8-256.

Froese, R. \& Pauly, D. (2020) FishBase. WorldWide Web Electronic Publication. Version May 2010. Available from: http:// www.fishbase.org (accessed 27 July 2021)

Garman, S. (1888) On an eel from the Marshall Islands. Bulletin of the Essex Institute, 20: 114-116. https://doi.org/10.5962/bhl.part.1574

Gosline, W.A. (1967) Reduction in branchiostegal ray number. Copeia, 1967 (1), 237-239. 
https://doi.org/10.2307/1442211

Günther, A. (1877) Preliminary notes on new fishes collected in Japan during the expedition of H. M. S. 'Challenger.' Annals and Magazine of Natural History, Series 4, 20 (119), 433-446.

https://doi.org/10.1080/00222937708682260

Günther, A. (1887) Report on the deep-sea fishes collected by H. M. S. Challenger during the years 1873-76. Report on the Scientific Results of the Voyage of H. M. S. Challenger, 22 (57), 1-268. https://doi.org/10.5962/bhl.title.15693

Ho, H.C., Smith, D.G., Tighe, K.A., Hibino, Y. \& McCosker, J.E. (2018) Checklist of eels of Taiwan (orders Anguilliformes and Saccopharyngiformes): An update. Zootaxa, 4454 (1), 5-17. https://doi.org/10.11646/zootaxa.4454.1.3

Homayuni, H., Marjani, M. \& Mousavi-Sabet, H. (2013) Descriptive key to the otoliths of three Sardinella species (Pisces, Clupeidae) from the northern Oman Sea. AACL Bioflux, 6 (3), 211-221.

Huang, J.-F., Ho, H.-C., Chang, Y.-H., Smith, D. G. \& Chen, H.-M. (2018) Two new species of the conger eel genus Bathycongrus (Anguilliformes: Congridae) from Taiwan. Zootaxa, 4454 (1), 107-117. https://doi.org/10.11646/zootaxa.4454.1.11

Hulet, W.H. (1978) Structure and functional development of the eel leptocephalus Ariosoma balearicum (De La Roche, 1809). Philosophical Transactions of the Royal Society of London. B, Biological Sciences, 282 (987), 107-138. https://doi.org/10.1098/rstb.1978.0010

Inoue, J.G., Miya, M., Miller, M.J., Sado, T., Hanel, R., Hatooka, K. \& Tsukamoto, K. (2010) Deep-ocean origin of the freshwater eels. Biology Letters, 6 (3), 363-366. https://doi.org/10.1098/rsbl.2009.0989

James, P.S.B.R. (1985) Comparative osteology of the fishes of the family Leiognathidae part I: Osteology. Indian Journal of Fisheries, 32 (3), 309-358.

Johnson, J.Y. (1862) Descriptions of some new genera and species of fishes obtained at Madeira. Proceedings of the Zoological Society of London, 2 (2), 167-180. https://doi.org/10.1111/j.1469-7998.1862.tb06491.x

Johnson, G.D., Ida, H., Sakaue, J., Sado, T., Asahida, T. \& Miya, M. (2012) A ‘living fossil’ eel (Anguilliformes: Protanguillidae, fam. nov.) from an undersea cave in Palau. Proceedings of the Royal Society B: Biological Sciences, 279 (1730), 934943. https://doi.org/10.1098/rspb.2011.1289

Jordan, D.S. \& Snyder, J.O. (1901) A review of the apodal fishes or eels of Japan, with descriptions of nineteen new species. Proceedings of the United States National Museum, 23 (1239), 837-890. https://doi.org/10.5479/si.00963801.23-1239.837

Kamohara, T. (1938) On the offshore bottom-fishes of Prov. Tosa, Shikoku, Japan. Maruzen Kobushiki Kaisha, Tokyo, 86 pp.

Kanazawa, R.H. (1958) A revision of the eels of the genus Conger with descriptions of four new species. Proceedings of the United States National Museum, 108 (3400), 219-267. https://doi.org/10.5479/si.00963801.108-3400.219

Karrer, C. (1983) Anguilliformes du Canal de Mozambique (Pisces, Teleostei). Faune Tropicale, 23 (1982), 1-116.

Klausewitz, W. \& Eibl-Eibesfeldt, I. (1959) Neue Röhrenaale von den Maldiven und Nikobaren (Pisces, Apodes, Heterocongridae). Senckenbergiana Biologica, 40 (3/4), 135-153.

Lacepède, B.G.E. (1803) Histoire naturelle des poissons. Hureau \& Monod 1973. Vol. 2. Chez F. G. Levrault, Paris, 323 pp.

Loh, K.-H., Chen, I.-S., Randall, J.E. \& Chen, H.-M. (2008) A review and molecular phylogeny of the moray eel subfamily Uropterygiinae (Anguilliformes: Muraenidae) from Taiwan, with description of a new species. The Raffles Bulletin of Zoology, 19, 135-150.

Lopez, J.A. \& Westneat, M.W. (2007) The phylogenetic affinities of the mysterious anguilliform genera, Coloconger and Thalassenchelys as supported by mtDNA Sequences. Copeia, 2007 (4), 959-966. https://doi.org/10.1643/0045-8511(2007)7[959:TPAOTM]2.0.CO;2

McClelland, J. (1844) Apodal fishes of Bengal. Calcutta Journal of Natural History, 5 (18), 151-226.

McCosker, J.E. (1998) Eels and their allies. In: Paxton, J.R. \& Eschmeyer, W.N. (Eds.), Encyclopedia of Fishes. $2^{\text {nd }}$ Edition. Academic Press, San Diego, California, pp. 85-90.

McCosker, J.E. \& Ho, H.-C. (2015) New species of the snake eels Echelus and Ophichthus (Anguilliformes: Ophichthidae) from Taiwan. Zootaxa, 4060 (1), 71-85. https://doi.org/10.11646/zootaxa.4060.1.11

Mehta, R.S. (2009) Ecomorphology of the moray bite: relationship between dietary extremes and morphological diversity. Physiological and Biochemical Zoology, 82 (1), 90-103. https://doi.org/10.1086/594381

Mehta, R.S. \& Wainwright, P.C. (2007) Raptorial jaws in the throat help moray eels swallow large prey. Nature, 449, 79-82. https://doi.org/10.1038/nature06062

Nelson, G.J. (1966) Gill arches of teleostean fishes of the order Anguilliformes. Pacific Science, 20, 391-408

Ramos-Castro, M., Chen, H.-M. \& Mao, B.-S. (2020) Descriptions of neurocranium morphology in 34 species of moray eels (Muraenidae) found in Taiwan. Zootaxa, 4810 (1), 81-109. 
https://doi.org/10.11646/zootaxa.4810.1.4

Reece, J.S., Bowen, B.W., Smith, D.G. \& Larson, A.F. (2010) Molecular phylogenetics of moray eels (Muraenidae) demonstrates multiple origins of shell-crushing jaw (Gymnomuraena, Echidna) and multiple colonizations of the Atlantic Ocean. Molecular Phylogenetics and Evolution, 57, 829-835. https://doi.org/10.1016/j.ympev.2010.07.013

Richardson, J. (1845) Ichthyology. Part 3. In: Hinds, R.B. (Ed.) The Zoology of the Voyage of H.M.S. Sulphur, under the Command of Captain Sir Edward Belcher, R.N., C.B., F.R.G.S., etc., during the Years 1836-42. Vol. 1. Smith, Elder and Co., London, pp. 99-150.

Richardson, J. (1848) Fishes. The Zoology of the Voyage of H. M. S. Samarang; under the Command of Captain Sir Edward Belcher, during the years 1843-1846. Reeve \& Benham, London, pp. 1-28.

Robins, C.R. (1989) The phylogenetic relationships of the anguilliform fishes. In: Böhlke E.B (Ed.), Fishes of the Western North Atlantic. Orders Anguilliformes and Saccopharyngiformes. 1 (Part 9). Sears Foundation for Marine Research, New Haven, Connecticut, pp. 9-23

Robins, C.H. \& Robins, C.R. (1971) Osteology and relationships of the eel family Macrocephenchelyidae. Proceedings of the Academy of Natural Sciences of Philadelphia, 1971, 127-150.

Rosenblatt, R.H. (1967) The osteology of the congrid eel Gorgasia punctata and the relationships of the Heterocongrinae. Pacific Science, 21 (1) 91-97.

Rüppell, W.P.S. in Klunzinger, C.B. (1871) Synopsis der Fische des Rothen Meeres. II. Theil. Verhandlungen der K.-K. zoologisch-botanischen Gesellschaft in Wien, 21, 441-688. https://doi.org/10.5962/bhl.title.1148

Santini, F., Kong, X., Sorenson, L., Carnevale, G., Mehta, R.S. \& Alfaro, M.E. (2013) A multi-locus molecular timescale for the origin and diversification of eels (Order: Anguilliformes). Molecular Phylogenetics and Evolution, 69 (3), 884-894. https://doi.org/10.1016/j.ympev.2013.06.016

Stransky, C. (2005) Geographic variation of golden redfish (Sebastes marinus) and deep-sea redfish (S. mentella) in the North Atlantic based on otolith shape analysis. Journal of Marine Science, 62 (8), 1691-1698. https://doi.org/10.1016/j.icesjms.2005.05.012

Tang, K.L. \& Fielitz, C. (2013) Phylogeny of moray eels (Anguilliformes: Muraenidae), with a revised classification of true eels (Teleostei: Elopomorpha: Anguilliformes). Mitochondrial DNA, 24 (1), 55-66. https://doi.org/10.3109/19401736.2012.710226

Tawa, A., Kobayakawa, M., Yoshimura, T. \& Mochioka, N. (2012) Identification of leptocephalus larvae of the tiger moray Scuticaria tigrina (Anguilliformes; Muraenidae) based on morphometric and genetic evidence. Ichthyological Research, 59 (4), 378-383. https://doi.org/10.1007/s10228-012-0292-0

Temminck, C.J. \& Schlegel, H. (1846) Pisces. In: Siebold, P. F. de (Ed.), Fauna Japonica, sive descriptio animalium, quae in itinere per Japoniam, jussu et auspiciis, superiorum, qui summum in India Batava imperium tenent, suscepto, annis 1823-1830 collegit, notis, observationibus et adumbrationibus illustravit Ph. Fr. de Siebold. Parts 10-14. Apud Arnz et Socios, Leiden, pp. 173-269.

https://doi.org/10.5962/bhl.title.124951

Tuset, V.M., Piretti, S., Lombarte, A. \& González, J.A. (2010) Using sagittal otoliths and eye diameter for ecological characterization of deep-sea fish: Aphanopus carbo and A. intermedius from NE Atlantic waters. Scientia Marina, 74 (4), 807-814.

https://doi.org/10.3989/scimar.2010.74n4807

Vasconcelos, A.J.M. \& Molina, W.F. (2009) Cytogenetical studies in five Atlantic Anguilliformes fishes. Genetics and Molecular Biology, 32 (1), 83-90. https://doi.org/10.1590/S1415-47572009005000015

Watanabe, S., Aoyama, J. \& Tsukamoto, K. (2004) Reexamination of Ege's (1939) use of taxonomic characters of the genus Anguilla. Bulletin of Marine Science, 74, 337-351.

Watanabe, S., Aoyama, J. \& Tsukamoto, K. (2009) A new species of freshwater eel Anguilla luzonensis (Teleostei: Anguillidae) from Luzon Island of the Philippines. Fisheries Science, 75, 387-392. https://doi.org/10.1007/s12562-009-0087-z

Wang, C.H., Kuo, C.H., Mok, H.K. \& Lee, S.C. (2003) Molecular phylogeny of elopomorph fishes inferred from mitochondrial 12S ribosomal RNA sequences. Zoologica Scripta, 32 (3), 231-241. https://doi.org/10.1046/j.1463-6409.2003.00114.x 